\title{
Gut Microbiota Abrogates Anti- $\alpha-$ Gal IgA Response in Lungs and Protects against Experimental Aspergillus Infection in Poultry
}

\author{
Lourdes Mateos-Hernández ${ }^{1,+} \oplus$, Veronica Risco-Castillo ${ }^{2,+}{ }^{\circledR}$, Edgar Torres-Maravilla ${ }^{3} \oplus$, \\ Luis G. Bermúdez-Humarán ${ }^{3}$ (D), Pilar Alberdi ${ }^{4}\left(\mathbb{D}\right.$, Adnan Hodžić ${ }^{5}$, \\ Angelica Hernández-Jarguin ${ }^{4,6}$, Sabine Rakotobe ${ }^{1}$, Clemence Galon ${ }^{1}$, Elodie Devillers ${ }^{1}$, \\ Jose de la Fuente ${ }^{4,7}$, Jacques Guillot ${ }^{2}$ and Alejandro Cabezas-Cruz ${ }^{1, *}$ (D) \\ 1 UMR BIPAR, INRAE, ANSES, Ecole Nationale Vétérinaire d'Alfort, Université Paris-Est, 14 rue Pierre et \\ Marie Curie, 94706 Maisons-Alfort, France; lourdes.mateos@vet-alfort.fr (L.M.-H.); \\ sabine.rakotobe@anses.fr (S.R.); clemence.galon@anses.fr (C.G.); elodie.devillers@anses.fr (E.D.) \\ 2 EA 7380 Dynamyc, UPEC, USC, ANSES, Ecole Nationale Vétérinaire d'Alfort, Université Paris-Est, \\ 94700 Maisons-Alfort, France; veronica.risco-castillo@vet-alfort.fr (V.R.-C.); jacques.guillot@vet-alfort.fr (J.G.) \\ 3 Micalis Institute, AgroParisTech, INRAE, Université Paris-Saclay, 78350 Jouy-en-Josas, France; \\ edgar.torres-maravilla@inrae.fr (E.T.-M.); luis.bermudez@inrae.fr (L.G.B.-H.) \\ 4 SaBio, Instituto de Investigación en Recursos Cinegéticos (IREC-CSIC-UCLM-JCCM), Ronda de Toledo s/n, \\ 13005 Ciudad Real, Spain; maria.alberdi@uclm.es (P.A.); AngelicaM.Hernandez@uclm.es (A.H.-J.); \\ jose_delafuente@yahoo.com (J.d.l.F.) \\ 5 Institute of Parasitology, Department of Pathobiology, University of Veterinary Medicine Vienna, \\ 1210 Vienna, Austria; Adnan.Hodzic@vetmeduni.ac.at \\ 6 Facultad de Medicina Veterinaria y Zootecnia, Universidad Autónoma de Tamaulipas, \\ Tamaulipas 87000, Mexico \\ 7 Department of Veterinary Pathobiology, Center for Veterinary Health Sciences, Oklahoma State University, \\ Stillwater, OK 74078, USA \\ * Correspondence: alejandro.cabezas@vet-alfort.fr; Tel.: +33-1-49-774-677 \\ + These authors contributed equally to this work.
}

Received: 4 May 2020; Accepted: 4 June 2020; Published: 7 June 2020

\begin{abstract}
Naturally occurring human antibodies (Abs) of the isotypes IgM and IgG and reactive to the galactose- $\alpha-1,3$-galactose ( $\alpha$-Gal) epitope are associated with protection against infectious diseases, caused by pathogens expressing the glycan. Gut microbiota bacteria expressing $\alpha$-Gal regulate the immune response to this glycan in animals lacking endogenous $\alpha$-Gal. Here, we asked whether the production of anti- $\alpha$-Gal Abs in response to microbiota stimulation in birds, confers protection against infection by Aspergillus fumigatus, a major fungal pathogen that expresses $\alpha$-Gal in its surface. We demonstrated that the oral administration of Escherichia coli O86:B7 strain, a bacterium with high $\alpha$-Gal content, reduces the occurrence of granulomas in lungs and protects turkeys from developing acute aspergillosis. Surprisingly, the protective effect of E. coli O86:B7 was not associated with an increase in circulating anti- $\alpha$-Gal IgY levels, but with a striking reduction of anti- $\alpha$-Gal IgA in the lungs of infected turkeys. Subcutaneous immunization against $\alpha$-Gal did not induce a significant reduction of lung anti- $\alpha-G a l \operatorname{IgA}$ and failed to protect against an infectious challenge with A. fumigatus. Oral administration of $E$. coli O86:B7 was not associated with the upregulation of lung cytokines upon A. fumigatus infection. We concluded that the oral administration of bacteria expressing high levels of $\alpha$-Gal decreases the levels of lung anti- $\alpha$-Gal IgA, which are mediators of inflammation and lung damage during acute aspergillosis.
\end{abstract}

Keywords: alpha-Gal; microbiota; aspergillosis; Aspergillus fumigatus; granulomas; cross-protective immunity 


\section{Introduction}

Galactose- $\alpha$-1,3-galactose ( $\alpha$-Gal) is an oligosaccharide abundantly expressed on the glycoproteins and glycolipids of non-primate mammals, prosimians, and New World monkeys and is synthesized by the enzyme $\alpha$-1,3-galactosyltransferase, encoded by the gene ggta1 [1]. Non-mammalian vertebrates including fish, amphibians, reptiles and birds do not express the $\alpha$-Gal epitope [1-3]. Humans, apes and Old World monkeys do not synthetize $\alpha$-Gal, presumably due to the functional inactivation of the gene ggta1 in the common ancestor of these animals [3], which resulted in the capacity to produce large amounts of antibodies (Abs) against the glycan epitope [4]. Bacteria from human gut microbiota also express $\alpha$-Gal on their surface and a continuous antigenic stimulation produce serum accumulation of natural anti- $\alpha$-Gal immunoglobulins $\mathrm{G}(\mathrm{IgG})$ and IgM [3,5]. Gut colonization by the bacterium Escherichia coli O86:B7 [6], which expresses high levels of $\alpha-\mathrm{Gal}[7,8]$, elicits the production of Abs with reactivity to $\alpha$-Gal and $\alpha$-Gal-related B blood group glycan in $\alpha$-Gal-deficient mice [9], non-human primates [10], chickens [11] and humans [12].

Based on the protective role of anti- $\alpha-\mathrm{Gal}$ Abs, it was suggested that the inactivation of ggta1 was due to strong selective pressure exerted on primate ancestors by an infectious agent, expressing $\alpha$-Gal [3]. In support to this hypothesis, gut colonization by E. coli O86:B7 elicits anti- $\alpha-G a l$ IgM that protected $\alpha$-Gal-deficient mouse against malaria transmission by Anopheles mosquitoes [8]. High levels of anti- $\alpha-$ Gal IgG and IgM in humans were associated with protection to Plasmodium sp., a pathogen expressing the antigen $\alpha$-Gal, in malaria endemic regions $[7,8]$. However, the $\alpha$-Gal immunity evolved as a trade-off between the protection to pathogens expressing $\alpha$-Gal, which is mediated by anti- $\alpha-\mathrm{Gal}$ $\operatorname{IgG}$ and IgM; and allergies, mediated by anti- $\alpha-G a l$ IgE [13]. Anti- $\alpha-G a l$ IgE production is associated with the onset of the $\alpha$-Gal syndrome (AGS), a type of allergy, triggered by tick bites and characterized by delayed hypersensitivity to consumed red meat products in humans [14-19]. Ticks synthetize $\alpha$-Gal [20], and several tick proteins in the saliva and cement have this glycan modification [17,20-23].

Aspergillosis, produced by the saprophytic opportunist fungus Aspergillus fumigatus with $\alpha$-Gal on its surface [24], is one of the most prevalent airborne fungal infections affecting humans and animals worldwide [25-27]. Aspergillus fumigatus can cause a life-threatening disease in immunosuppressed and vulnerable individuals. Clinical presentation of aspergillosis varies according to the infectious load and the immunocompetence of the host. In humans, acute aspergillosis emerges as one of the first medical concerns in immunocompromised patients, especially those submitted to bone marrow or solid-organ transplantation or patients with cancer or HIV [25,27]. Despite the infective stage of A. fumigatus, the conidia, expresses high levels of $\alpha-\mathrm{Gal}$ on its outer wall and the epitope is exposed to the host immune system; no difference in the levels of circulating anti- $\alpha-G a l$ IgG, $\operatorname{IgM}$ and $\operatorname{IgE}$ was found in patients with invasive aspergillosis and healthy control individuals [24]. In animals, vulnerability to Aspergillus infection varies among host species, with birds exhibiting the highest susceptibility. Among galliform species, infected turkey poults have high morbidity and mortality rates [26]. Clinical signs are usually unexpected and particularly severe, and mortality remains high even after antifungal treatment [28]. Lung damage is commonly found in several forms of aspergillosis in birds [29,30] and humans [31]. The gut-lung microbiota axis may influence the pathogenesis of aspergillosis [32]. However, the mechanisms by which microbiota drives the pathogenesis of aspergillosis are poorly understood [32]. Particularly, the capacity of gut microbiota to elicit anti- $\alpha-G a l$ IgA in the lungs, and the role of these Abs as mediators of inflammation and immunity in human and non-mammalian vertebrates have not been explored in the context of aspergillosis.

To address this gap, experimentally Aspergillus-infected turkeys Meleagris gallopavo and chickens Gallus gallus domesticus $[30,33,34]$ were used in this study, to explore the role of gut microbiota and anti- $\alpha$-Gal immunity for the control of aspergillosis. The results of this study showed that gut microbiota enriched with bacteria expressing high levels of $\alpha$-Gal protects turkeys against clinical aspergillosis and the formation of lung granulomas, by reducing lung anti- $\alpha$-Gal IgA to residual levels. 


\section{Materials and Methods}

\subsection{Ethics Statement}

All procedures in this work were performed according to the principles established by the French and International Guiding Principles for Biomedical Research Involving Animals (2012). The regional ethics committee for animal experimentation at the Veterinary College of Alfort approved this research (Anses/EnvA/UPEC, approval No. 10/03/15-11).

\subsection{Environmental Contamination Assessment}

The absence of fungal contamination was assessed in the environment, litter and feedstuff using malt-chloramphenicol agar plates (AEMTEK, Fremont, CA, USA). Fungal contamination of the environment was assessed before starting and during the experiment by sampling of conidia by sedimentation on two opened agar plates placed in different points of the room for 30 min. Litter and feedstuff ( $1 \mathrm{~g}$ each) were mixed in $45 \mathrm{~mL}$ of phosphate-buffered saline (PBS, $10 \mathrm{mM} \mathrm{NaH}_{2} \mathrm{PO}_{4}$, $2.68 \mathrm{mM} \mathrm{KCl}, 140 \mathrm{mM} \mathrm{NaCl}$, pH 7.2, Thermo Scientific, Waltham, MA, USA) containing 0.01\% (vol/vol) Tween 20 (PBST) and $100 \mu \mathrm{L}$ of the mix were seeded in agar plates. All plates were incubated at $37^{\circ} \mathrm{C}$ during at least $48 \mathrm{~h}$.

\subsection{Animals and Housing Conditions}

One-day-old female turkeys Hybrid Diamond White Medium strain (Grimaud Frères Sélection, La Corbière, France) and chickens Lohmann Brown strain (Lohmann France, Le Grand Moulin, France) were purchased with an average weight of 65-70 g and 40-50 g, respectively. The animals were housed in cages (Ducatillon, Cysoing, France) under specific-pathogen-free (SPF) conditions in the biosafety level 3 sector of the animal facility of the Veterinary College of Alfort (CRBM-EnvA, Maisons-Alfort, France). Fresh commercial turkey feed 'dindonneau pintadeau uni S25' (Axereal, Olivet, France, ref. 1930920) and chicken starter feed 'gold $1 \& 2$ crumble 5 kg' (Versele-Laga, Deinze, Belgium, ref. 283.0250) and fresh water were provided ad libitum. The photoperiod cycles (14 h per day) and room temperature $\left(25^{\circ} \mathrm{C}\right)$ were controlled. Additional heat was provided by two infrared lamps located close to the animals. At no point were the animals used in this study placed under antibiotic treatment.

\subsection{Aspergillus fumigatus Strain and Inoculum Preparation}

The highly germinative A. fumigatus CBS 144.89 (CEA10) clinical strain was used for all experiments [35]. All mycological cultures were performed on Sabouraud dextrose agar (SDA), supplemented with chloramphenicol $(5 \mathrm{mg} / \mathrm{L})$ and incubated at $37^{\circ} \mathrm{C}$ for 10 days. Sub-cultures were performed twice a week. To prepare the inoculum, $A$. fumigatus colonies were grown for $2-3$ days at $37^{\circ} \mathrm{C}$. Conidia were subsequently harvested by resuspension in PBST, filtered in a $70 \mu \mathrm{m}$ diameter nylon cell strainer (ClearLine Dominique Dutscher, Brumath, France), washed by centrifugation at $3500 \times g$ for $10 \mathrm{~min}$, resuspended in PBST and then counted using a Malassez counting chamber. The inoculum of $A$. fumigatus contained $4 \times 10^{7}$ conidia resuspended in $200 \mu \mathrm{L}$ of PBST [30]. All reagents used for inoculum preparation were apyrogenic.

\subsection{Detection of $\alpha$-Gal Glycan in Fungi}

The presence of $\alpha$-Gal in A. fumigatus (Ascomycota) was detected by immunofluorescence, flow cytometry and inhibition ELISA. The presence of $\alpha$-Gal modification in proteins of other Ascomycota (i.e., Aspergillus nidulans, Candida glabrata, Candida albicans, Microsporum canis, Penicillium sp., Scedosporium sp., and Trichophyton benhamiae) and Zygomycota (i.e., Mucor sp. and Rhizopus sp.) fungi was assessed by inhibition ELISA. 
For immunofluorescence, A. fumigatus conidia were cultured as described above and hyphae were separated from SDA media using PBS by gently scrapping. Conidia and hyphae were washed in PBS and then fixed and permeabilized with the Intracell fixation and permeabilization kit (Immunostep, Salamanca, Spain), following manufacturer recommendations. Fixed conidia and hyphae were incubated for $1 \mathrm{~h}$ at room temperature (RT) with 3\% Human Serum Albumin (HSA, Sigma-Aldrich, St. Louis, MO, USA) in PBS. The monoclonal mouse anti- $\alpha$-Gal antibody (mAb) M86 (Enzo Life Sciences, Farmingdale, NY, USA) diluted 1:50 in 3\% HSA/PBS was used as primary Ab (incubation for $14 \mathrm{~h}$ at $4{ }^{\circ} \mathrm{C}$ ) and the FITC-conjugated goat anti-mouse IgM (Abcam, Cambridge, UK) diluted 1:200 in 3\% HSA/PBS as a secondary Ab (incubation for $1 \mathrm{~h}$ at RT). Hyphal mitochondria were stained with Mitotracker Red (Thermo Scientific, Waltham, MA, USA). Aliquots of fixed and stained conidia were used for immunofluorescence assays, mounted in glass slides using ProLong Antifade (Thermo Scientific, Waltham, MA, USA) with DAPI reagent (Molecular Probes, Eugene, OR, USA) and examined using a Zeiss LSM 800 laser scanning confocal microscope (Carl Zeiss, Oberkochen, Germany) with oil immersion objectives.

The detection of $\alpha$-Gal by flow cytometry was performed as previously described [20,24]. Briefly, samples were analyzed on a FACSCalibur flow cytometer equipped with CellQuest Pro software (BD Bio-Sciences, Madrid, Spain). The cell population was gated according to forward-scatter and side-scatter parameters. The human promyelocytic leukemia HL60 cells, that do not express $\alpha$-Gal, were included as a negative control. The mean and median fluorescence intensity of HL60 and conidia was recorded and compared.

Fungal proteins were extracted with six steel balls using the homogenizer Precellys ${ }^{\circledR} 24$ Dual (Bertin, Montigny-le-Bretonneux, France) at $6000 \mathrm{rpm}$ for $30 \mathrm{~s}$, followed by cool down in ice, 3 times in PBS-1\% triton and quantified by Bicinchoninic Acid (BCA) Protein Assay Kit (ThermoFisher, Waltham, MA, USA) with Bovine Serum Albumin (BSA) as standard.

For inhibition ELISA, the inhibition of M86 binding to Gal $\alpha 1-3 \mathrm{Gal}$ linked to HSA (Gal $\alpha 1-3 \mathrm{Gal}-\mathrm{HSA}$, Dextra Laboratories, Reading, UK) was calculated after pre-incubation of M86 with fungal proteins. Briefly, 96-well ELISA plates (Nunc-ImmunoTM Plate, Roskilde, Denmark) were coated overnight at $4{ }^{\circ} \mathrm{C}$ with Gal $\alpha 1-3 \mathrm{Gal}-H S A(200 \mathrm{ng} /$ well), diluted in carbonate/bicarbonate buffer $(0.05 \mathrm{M}, \mathrm{pH} 9.6)$. The wells were washed three times with $150 \mu \mathrm{L}$ of PBST and then blocked with $0.5 \%$ HSA/PBST for $1 \mathrm{~h}$ at RT. The mAb M86 diluted 1:200 was pre-incubated overnight at $4{ }^{\circ} \mathrm{C}$ and constant shaking of $300 \mathrm{rpm}$ with two concentrations of fungal proteins (i.e., $0.5 \mu \mathrm{g} / \mathrm{mL}$ and $1.5 \mu \mathrm{g} / \mathrm{mL}$ ). Pre-incubation with $\alpha$-Gal-BSA and protein extract of ggta1 knockout (KO) Sus scrofa (pig) were used as positive and negative controls, respectively. The protein-mAb M86 complexes were removed by centrifugation at $16,000 \times g$ for $30 \mathrm{~min}$ at $4{ }^{\circ} \mathrm{C}$. The supernatant (containing free $\mathrm{mAb}$ M86) was then collected and added to the Gal $\alpha 1-3 \mathrm{Gal}-\mathrm{HSA}$-coated wells for $1 \mathrm{~h}$ at $37^{\circ} \mathrm{C}$. The plates were washed three times and horseradish peroxidase (HRP)-conjugated goat anti-mouse IgM Ab diluted 1:2000 was used as secondary $\mathrm{Ab}$ and incubated at RT for $1 \mathrm{~h}$. The plates were washed three times and the reaction was developed by adding $100 \mu \mathrm{L}$ ready-to-use tetramethylbenzidine-hydrogen peroxide (TMB) solution (Promega, Madison, WI, USA) at RT for $20 \mathrm{~min}$ in the dark, and then stopped with $50 \mu \mathrm{L}$ of $0.5 \mathrm{M}$ $\mathrm{H}_{2} \mathrm{SO}_{4}$. The optical densities (OD) were measured at $450 \mathrm{~nm}$ using an ELISA plate reader (Filter-Max F5, Molecular Devices, San Jose, CA, USA). All samples were tested in triplicate and the average value of three blanks (no Abs) was subtracted from the reads. The cut-off was determined as two times of a mean OD value of the blank controls. The percentage of M86-binding inhibition was calculated using the average OD of each sample as $100-(100 \times$ OD (M86 after pre-incubation with fungal proteins or $\alpha$-gal-BSA or protein extract of ggta1 KO pigs)/OD (M86 without pre-incubation)).

\subsection{Bacteria Culture and Oral Administration of Bacteria}

The bacterium E. coli O86:B7 (ATCC 12701) expresses high levels of $\alpha$-Gal on its surface [7,8], which is not the case for E. coli BL21 (DE3, Invitrogen, Carlsbad, CA, USA) [7]. The E. coli strains were grown on $50 \mathrm{~mL}$ of Luria Broth (Sigma-Aldrich, St. Louis, MO, USA), incubated at $37{ }^{\circ} \mathrm{C}$ with vigorous 
shaking overnight, washed twice with PBS, centrifuged at $4000 \times g$ for 5 min at $4{ }^{\circ} \mathrm{C}$ and re-suspended at a concentration of $\sim 1 \times 10^{10}$ colony-forming units (CFU)/mL of PBS. For oral administration of bacteria, 7-day-old turkeys $(n=20)$ received E. coli strain O86:B7 $(n=10)$ or E. coli strain BL21 $(n=10)$ $\left(\sim 1 \times 10^{9} \mathrm{CFU}\right.$ in $100 \mu \mathrm{L}$ of PBS $)$ via oral gavage at days $0,1,3,7,8,9,14,15$ and 16 . All reagents used for bacterial preparation were apyrogenic.

\subsection{Immunization}

For immunization, 7-day-old turkeys $(n=20)$ and chickens $(n=10)$ were immunized subcutaneously with synthetic Gal $\alpha 1-3$ Gal conjugated to BSA ( $\alpha$-Gal-BSA, Dextra Laboratories, Reading, UK) $(75 \mu \mathrm{g} / \mathrm{bird})$, in $200 \mu \mathrm{L}$ of the water-in-oil emulsion of $70 \%$ Montanide ISA adjuvant (SEPPIC, Castres, France), with a boost 2 weeks later (day 14). Control animals received a mock vaccine containing PBS and adjuvant.

\subsection{Intratracheal Challenge with A. fumigatus}

The intratracheal challenge was performed on day 27. Before fungal inoculation, birds were anesthetized by inhalation of 5\% isoflurane (Aerrane, Baxter, Maurepas, France) in oxygen until unconsciousness. Inoculation of $A$. fumigatus was performed using a $1 \mathrm{~mL}$ syringe (Medallion, Merit Medical, The Netherlands), fitted with a stainless steel 19-gauge aerosolizer (Microsprayer IA-1B, Penn Century, Wyndmoor, PA, USA). The gauge was inserted through the oropharynx into the trachea under visual control. After challenge, birds were monitored twice a day on a daily basis. Respiratory signs of avian aspergillosis (i.e., open-mouthed breathing, gasping and hyperpnea) were recorded. Animals were sacrificed 4 days after challenge.

\subsection{Euthanasia, Lung Lesions Score and Sample Collection}

On day 31, four days after the infectious challenge, birds were anesthetized and euthanized by occipital sinus injection of $182.20 \mathrm{mg} / \mathrm{kg}$ of sodium pentobarbital (Dolethal, Vetoquinol, Lure, France). The respiratory tract was removed aseptically under a laminar flow cabinet and the presence and size of lesions in the right and left lungs were registered. Observed lung lesions varied among congestive, hemorrhagic or consolidated/indurated lesions. They were classified according to the following score: no lesions (minimum score, 0); small lesions between $1 \mathrm{~cm}^{2}$ and $2 \mathrm{~cm}^{2}$ (score 1); moderate-size lesions between $3 \mathrm{~cm}^{2}$ and $4 \mathrm{~cm}^{2}$ (score 2) and extensive lesions with more than $4 \mathrm{~cm}^{2}$ and covering almost all the area of the lungs (maximum score, 3 ). The statistical differences between groups were evaluated using one-way ANOVA with Dunnett's multiple comparison test applied for individual comparisons (for the groups treated with E. coli O86:B7, E. coli BL21 and PBS) and the unpaired non-parametric Mann-Whitney $U$ test (for the groups immunized with $\alpha$-Gal-BSA and the mock vaccine) in the GraphPad 5 Prism program (GraphPad Software Inc., San Diego, CA, USA). Differences were considered significant when $p<0.05$.

Blood samples were collected on days $0,7,14$ and 31 on sterile tubes without anticoagulant. For serum separation, the blood samples were incubated for 20-30 min at RT, allowing for clotting, and then centrifuged at $1500 \times g$ for $20 \mathrm{~min}$ at RT. After necropsy, samples from the right and left lungs were aseptically collected and conserved according to the analysis to be performed: samples for DNA (for A. fumigatus $28 S$ quantification by quantitative PCR (qPCR)), RNA (for cytokines mRNA quantification by qPCR) and protein (for anti- $\alpha$-Gal IgA quantification) extraction were placed immediately in liquid nitrogen; samples for histopathology were immediately fixed in $10 \%$ Neutral Buffered Formalin (NBF) and the samples for CFU assay were conserved in PBST on ice until processing. Ceca samples were also collected (for RNA extraction and cytokines quantification by qPCR) and placed immediately in liquid nitrogen. 


\subsection{Indirect ELISA for Anti- $\alpha-G a l \operatorname{Ig} Y$ and $\operatorname{Ig} A$ Levels Determination}

To evaluate the levels of specific Abs against Gal $\alpha 1-3 \mathrm{Gal}$ and Gal $\alpha 1-3 \mathrm{Gal} \beta 1-4 \mathrm{GlcNAc}$ in turkey and chicken sera, 96-well ELISA plates (Thermo Scientific, Waltham, MA, USA) were coated with $100 \mu \mathrm{L} /$ well of either Gal $\alpha 1-3 \mathrm{Gal}-\mathrm{HSA}$ and Gal $\alpha 1-3 \mathrm{Gal} \beta 1-4 \mathrm{GlcNAc}$ linked to HSA $(0.5 \mu \mathrm{g} / \mathrm{mL}$, Dextra Laboratories, Reading, UK) and incubated overnight at $4{ }^{\circ} \mathrm{C}$. The antigens were diluted in carbonate/bicarbonate buffer (0.05 M, pH 9.6) and incubated overnight at $4{ }^{\circ} \mathrm{C}$. Optimal antigen concentration and dilutions of sera and conjugate were defined using a titration assay. Wells were washed three times with $150 \mu \mathrm{L}$ of PBST and then blocked by adding $100 \mu \mathrm{L}$ of $1 \%$ HSA/PBST for $1 \mathrm{~h}$ at RT. After three washes, serum samples, diluted in 0.5\% HSA/PBST (1:500), were added to the wells and incubated for $1 \mathrm{~h}$ at $37^{\circ} \mathrm{C}$. The plates were washed three times and HRP-conjugated Abs (goat anti-turkey IgY) (Mybiosource, San Diego, CA, USA) goat anti-chicken IgY (Sigma-Aldrich, St. Louis, MO, USA) or goat anti-chicken IgA (CliniScience, Nanterre, France) were added at 1:2000 dilution in 0.5\% HSA/PBST (100 $\mu \mathrm{L} /$ well) and incubated for $1 \mathrm{~h}$ at RT. The plates were washed three times and the reaction was developed by adding $100 \mu \mathrm{L}$ ready-to-use TMB solution (Promega, Madison, WI, USA) at RT for 20 min in the dark, and then stopped with $50 \mu \mathrm{L}$ of $0.5 \mathrm{M} \mathrm{H}_{2} \mathrm{SO}_{4}$. The OD were measured at $450 \mathrm{~nm}$ using an ELISA plate reader (Filter-Max F5, Molecular Devices, San Jose, CA, USA). All samples were tested in triplicate and the average value of three blanks (no Abs) was subtracted from the reads. The cut-off was determined as two times a mean OD value of the blank controls.

Determination of anti- $\alpha$-Gal IgA levels in the lungs was performed as above, but using total lung proteins (600 ng), extracted by the TRI Reagent kit (Thermo Scientific, Waltham, MA, USA), following manufacturer recommendations. The statistical differences between groups were evaluated using one-way ANOVA with Dunnett's multiple comparison test applied for individual comparisons in the GraphPad 5 Prism program (GraphPad Software Inc., San Diego, CA, USA). Differences were considered significant when $p<0.05$.

\subsection{Enzymatic Removal of $\alpha$-Gal to Test the Specificity of Turkey Anti- $\alpha$-Gal Abs}

To assess the specificity of anti- $\alpha$-Gal Abs in turkeys, the Gal $\alpha 1-3 \mathrm{Gal}-\mathrm{HSA}$ antigen (Dextra Laboratories, Reading, UK) was immobilized on an ELISA plate (50 ng/well), and treated or not with $\alpha$-galactosidase from green coffee beans (Sigma-Aldrich, St. Louis, MO, USA), following the procedure described elsewhere [36]. Before the treatment, the enzyme was centrifuged at $10,000 \times g$ for $10 \mathrm{~min}$ at $4{ }^{\circ} \mathrm{C}$, to remove the ammonium sulfate. The supernatant was discarded and $100 \mathrm{mM}$ potassium phosphate buffer ( $\mathrm{pH}$ 6.5) was added to the pellet, so the final concentration of the enzyme solution was $50 \mathrm{mU} / 100 \mu \mathrm{L}$. The plate was then incubated at $37^{\circ} \mathrm{C}$ for $24 \mathrm{~h}$ in a humidified plastic chamber to avoid evaporation. After the incubation, wells were washed five times with $150 \mu \mathrm{L}$ of PBST and the indirect ELISA was performed as described above. Sera samples from the turkeys treated with E. coli O86:B7 $(n=5)$, E. coli BL21 $(n=5)$ and PBS $(n=5)$ were randomly selected and used in the specificity assay. The statistical differences of sera reactivity against treated and non-treated antigen were evaluated using the Wilcoxon signed rank test in the GraphPad 5 Prism program (GraphPad Software Inc., San Diego, CA, USA). Differences were considered significant when $p<0.05$.

\subsection{Histopathology and Histopathological Scores}

Lung samples collected for histopathology were immediately fixed in 10\% NBF for $48 \mathrm{~h}$, then dehydrated in successive baths of ethanol (from 70 to 100\%) and embedded in paraffin blocks using Fully Automated Innovative Tissue Processor LOGOS One (Milestone, Sorisole, Italy). Thick sections of $4 \mu \mathrm{m}$ were cut out of the paraffin specimens and placed in slides. The slides were automatically stained with hematoxylin-eosin-saffron (HES), using Leica ST5010-CV5030 Integrated Workstation (Leica, Nanterre, Germany). Periodic Acid-Schiff (PAS) staining was performed using the PAS kit (Sigma-Aldrich, St. Louis, MO, USA), following the manufacturer's instructions. A blind reading of five fields $(100 \times)$ per slide of the right and left lungs of each turkey was conducted to visualize 
microscopic lesions associated with inflammation and granulomas (using slides stained with HES) and the presence of Aspergillus-like hyphae (using slides stained with PAS). Microscopic observations in each field were recorded and scored as follows for HES: absence of leukocyte infiltrate and peribronchial regions visible (minimum score, 0 ); leukocyte infiltrate surrounding peribronchial regions without lumen stenosis (score 1); intense leukocyte infiltrate and lumen of peribronchial regions is not visible (score 2); and the presence of granulomas (maximum score, 3)

Fungal presence by PAS was scored as follows: absence of fungal elements (minimum score, 0); presence of isolated germtube/hyphae (score 1), presence of several branching hyphae (mycelium) inside granulomas between 20 and $25 \mu \mathrm{m}^{2}$ (score 2) and presence of mycelium inside granulomas larger than $25 \mu^{2}$ (maximum score, 3). The scores of the five-field readings per slide and per staining were used to calculate the HES and PAS scores per lung and per animal. The statistical differences between groups were evaluated using one-way ANOVA with Dunnett's multiple comparison test applied for individual comparisons (for the groups treated with E. coli O86:B7, E. coli BL21 and PBS) and the unpaired non-parametric Mann-Whitney $U$ test (for the groups immunized with $\alpha$-Gal-BSA and the mock vaccine) in the GraphPad 5 Prism program (GraphPad Software Inc., San Diego, CA, USA). Differences were considered significant when $p<0.05$.

\subsection{Quantification of A. fumigatus by CFU and qPCR Assays}

For CFU counting, $100 \mathrm{mg}$ of right lungs were individually ground in $5 \mathrm{~mL}$ of PBST using the Bio-Gen PRO200 Tissue Homogenizer (PRO Scientific, Oxford, CT, USA). An aliquot of the lung homogenate $(100 \mu \mathrm{L})$ was immediately spread on SDA plates and incubated at $37^{\circ} \mathrm{C}$ for 24 to $48 \mathrm{~h}$, after which $A$. fumigatus colonies counting was performed. For qPCR, genomic DNA was extracted from $25 \mathrm{mg}$ of the right lungs. The lung samples were individually crushed in $180 \mu \mathrm{L}$ of Lysis Buffer (QIAamp DNA Mini Kit, Qiagen, Courtaboeuf, France) with glass beads using the Tissue Homogenizer 125 Precellys 24 (Bertin Technologies, Montigny-le-Bretonneux, France) at $6000 \mathrm{rpm}$ for $30 \mathrm{~s}$. The homogenization procedure was repeated three times with a $30 \mathrm{~s}$ cooling period in ice in between cycles. DNA extraction was completed using the QIAamp DNA Mini Kit (Qiagen, Courtaboeuf, France), according to the manufacturer's instructions.

qPCR was performed with $100 \mathrm{ng}$ of genomic DNA targeting $A$. fumigatus $28 S$ gene with SYBR Green LightCycler 480 Master mix (Roche, Meylan, France). The selection of A. fumigatus $28 S$ gene for fungal quantification was based on previously published research [30]. All assays were run under the same conditions as follow: $50{ }^{\circ} \mathrm{C}$ for $2 \mathrm{~min}, 95^{\circ} \mathrm{C}$ for $10 \mathrm{~min}$, and 45 cycles of $15 \mathrm{~s}$ at $95{ }^{\circ} \mathrm{C}$ and $1 \mathrm{~min}$ at $60^{\circ} \mathrm{C}$. The CT values were recorded, and the relative levels of fungal DNA were normalized against turkey $\beta$ actin ( $a c t b)$ and glyceraldehyde-3-phosphate dehydrogenase ( $g a p d h)$ and chicken gapdh as host genes. Relative quantification was achieved using the $2^{-\Delta \Delta C t}$ ratio method [37]. Primers were designed using Primer-BLAST online software [38] and are presented in Table 1. The statistical differences between groups were evaluated using one-way ANOVA with Dunnett's multiple comparison test applied for individual comparisons (for the groups treated with E. coli O86:B7, E. coli BL21 and PBS) and the unpaired non-parametric Mann-Whitney $U$ test (for the groups immunized with $\alpha$-Gal-BSA and the mock vaccine) in the GraphPad 5 Prism program (GraphPad Software Inc., San Diego, CA, USA). Differences were considered significant when $p<0.05$. 
Table 1. Primers used in this study.

\begin{tabular}{|c|c|c|c|c|c|}
\hline Gene & Target Species & $\begin{array}{l}\text { NCBI Target } \\
\text { Gene(s) }\end{array}$ & Forward Primer & Reverse Primer & $\begin{array}{l}\text { Target } \\
\text { Length }\end{array}$ \\
\hline gapdh & Chicken Turkey & $\begin{array}{l}\text { NM_204305 } \\
\text { NM_001303179 }\end{array}$ & CCACATGGCATCCAAGGAGT & CTCCAACAAAGGGTCCTGCT & $74 \mathrm{bp}$ \\
\hline$\beta$-actin & Chicken Turkey & $\begin{array}{l}\text { L08165.1 } \\
\text { AY942620.1 }\end{array}$ & GAGAAATTGTGCGTGACATCA & СCTGAACCTCTCATTGCCA & $114 \mathrm{bp}$ \\
\hline IL2 & $\begin{array}{l}\text { Chicken } \\
\text { Turkey }\end{array}$ & $\begin{array}{l}\text { AF017645 } \\
\text { AJ007463 }\end{array}$ & $\begin{array}{l}\text { TTGGCTGTATTTCGGTAGCA } \\
\text { GAGCATCGCTATCACCAGAA }\end{array}$ & $\begin{array}{l}\text { TCCTGGGTCTCAGTTGGTGT } \\
\text { GCAGAGTTTGCTGACTGCAC }\end{array}$ & $\begin{array}{l}160 \mathrm{bp} \\
141 \mathrm{bp}\end{array}$ \\
\hline IL6 & Chicken Turkey & $\begin{array}{l}\text { AJ309540 } \\
\text { XM_003207130 }\end{array}$ & AGGGCCGTTCGCTATTTGAA & ACGGAACAACACTGCCATCT & $112 \mathrm{bp}$ \\
\hline IL10 & Turkey & NM_001303189 & GCTGCGCTTCTACACAGATG & TCCCGTTCTCATCCATCTTC & $203 \mathrm{bp}$ \\
\hline IL4 & Turkey & NM_001303181.1 & AGAGCTCATTGCCTCCACAC & ATTGCAAGGGACCTGCTCTC & $72 \mathrm{bp}$ \\
\hline MyD88 & Turkey & XM_019616228.1 & TTACGAAGGAAGCAGCAGGAG & TGGCAAGACATCCCGATCAA & $208 \mathrm{bp}$ \\
\hline$I F N-\gamma$ & Turkey & XM_003202048 & CTGAAGAACTGGACAGAGAG & CACCAGCTTCTGTAAGATGC & $264 \mathrm{bp}$ \\
\hline $28 \mathrm{~S}$ & A. fumigatus & NG_055745.1 & CTCGGAATGTATCACCTCTCGG & TCCTCGGTCCAGGCAGG & $29 \mathrm{bp}$ \\
\hline
\end{tabular}

\subsection{RNA Extraction and Quantification of Cytokines $m R N A$ Levels by $q P C R$}

Total RNA was extracted from $100 \mathrm{mg}$ of right lung and ceca samples. Tissue samples were individually crushed in $1 \mathrm{~mL}$ of TRI Reagent (Thermo Scientific, Waltham, MA, USA) with glass beads using the Tissue Homogenizer 125 Precellys 24 (Bertin Technologies, Montigny-le-Bretonneux, France) at $6000 \mathrm{rpm}$ for $30 \mathrm{~s}$. The homogenization procedure was repeated three times. Complementary DNAs (cDNA) were obtained by reverse transcription of total RNA $(1 \mu \mathrm{g})$ using random primers and the SuperScript VILO cDNA Synthesis Kit (Thermo Scientific, Waltham, MA, USA). Equal amounts of cDNA per sample (10 ng) were used in triplicate assays for qPCR amplification using the SYBR Green LightCycler 480 Master mix (Roche, Meylan, France) with $0.3 \mu \mathrm{M}$ of each primer for the genes IL2, IFN $\gamma$, MyD88, IL6 and IL10 (Table 1). The LightCycler 480 System Thermocycler (Roche, Basilea, Suiza) was used. The qPCR assays were run under the following conditions: $50^{\circ} \mathrm{C}$ for $2 \mathrm{~min}, 95^{\circ} \mathrm{C}$ for $10 \mathrm{~min}$, then $45 \mathrm{cycles}$ of $15 \mathrm{~s}$ at $95^{\circ} \mathrm{C}$ and $1 \mathrm{~min}$ at $60^{\circ} \mathrm{C}$. The $\mathrm{CT}$ values were recorded and the $2^{-\Delta \Delta C t}$ method [37] was used to calculate the relative gene expression values with turkey $a c t b$ and gapdh and chicken gapdh as the endogenous control genes. Statistical differences between groups for each gene were evaluated using one-way ANOVA with Dunnett's multiple comparison test applied for individual comparisons in the GraphPad 5 Prism program (GraphPad Software Inc., San Diego, CA, USA). Differences were considered significant when $p<0.05$.

\section{Results}

\subsection{A. fumigatus Contains the Carbohydrate $\alpha$-Gal}

Immunofluorescence labeling using the anti- $\alpha$-Gal mAb M86 [39] confirmed the presence of $\alpha$-Gal glycan on the surface and cytoplasm of A. fumigatus conidia (Figure 1A), as well as in the cytoplasm of the hyphae and forming granular structures on the surface of hyphal stretches (Figure 1B,C).

The binding of the mAb M86 to $\alpha$-Gal epitopes in A. fumigatus was further confirmed by flow cytometry (Figure 1D [24]). Different $\alpha$-Gal levels were recorded by flow cytometry in different proportions of the conidia population [24]. The association of $\alpha$-Gal to fungal proteins was assessed by an inhibition ELISA in which the reactivity of $\mathrm{mAb}$ M86 was measured following a pre-incubation with proteins extracted from Ascomycota species, including A. fumigatus, Aspergillus nidulans, Candida glabrata, Candida albicans, Microsporum canis, Penicillium sp., Scedosporium sp., and Trichophyton benhamiae and the Zygomycota fungi Mucor sp. and Rhizopus sp. A significant inhibition of M86 binding to Gal $\alpha 1-3$ Gal-HSA was observed after incubation with increasing concentrations of $A$. fumigatus and Mucor sp. proteins which suggests that among the tested fungi, $\alpha-G a l$ is only present in A. fumigatus and Mucor sp. (Figure 1E). 
A

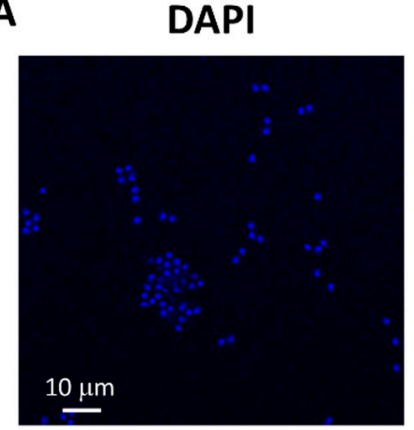

B

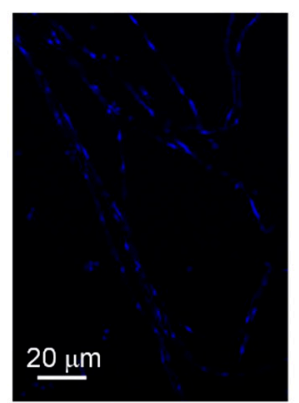

D

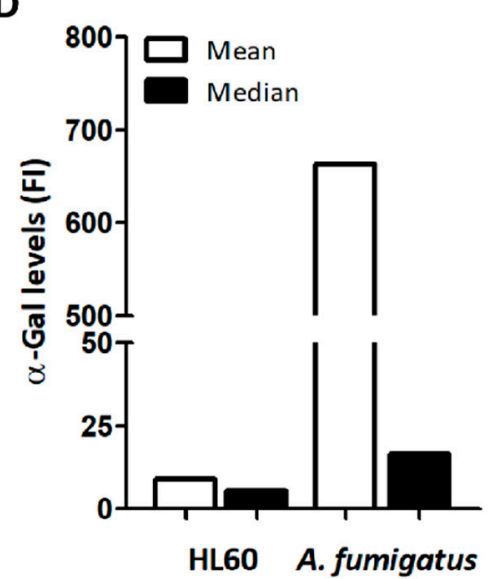

FITC

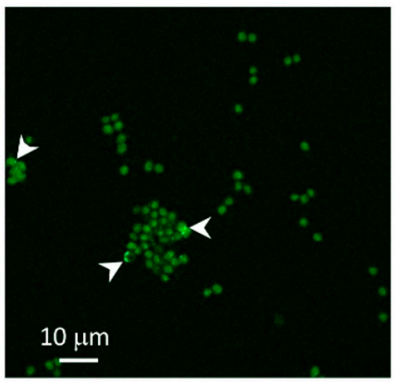

FITC

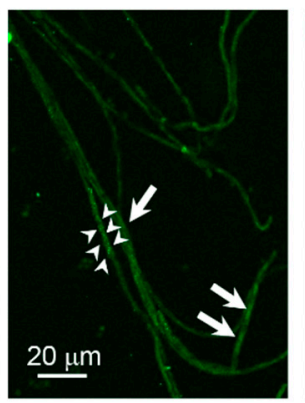

Mitotracker

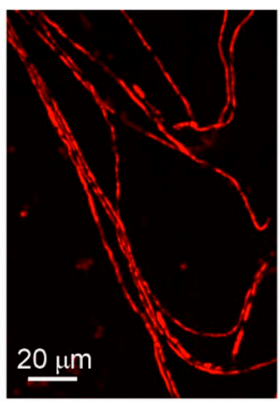

Merged

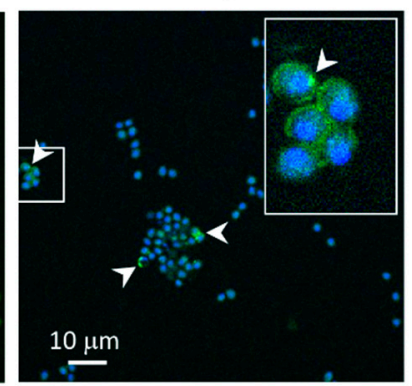

Merged C
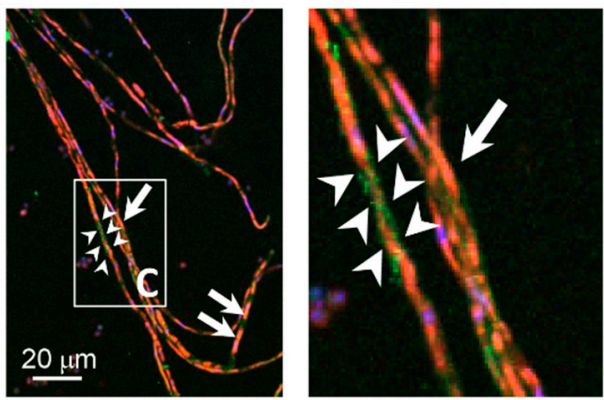

E

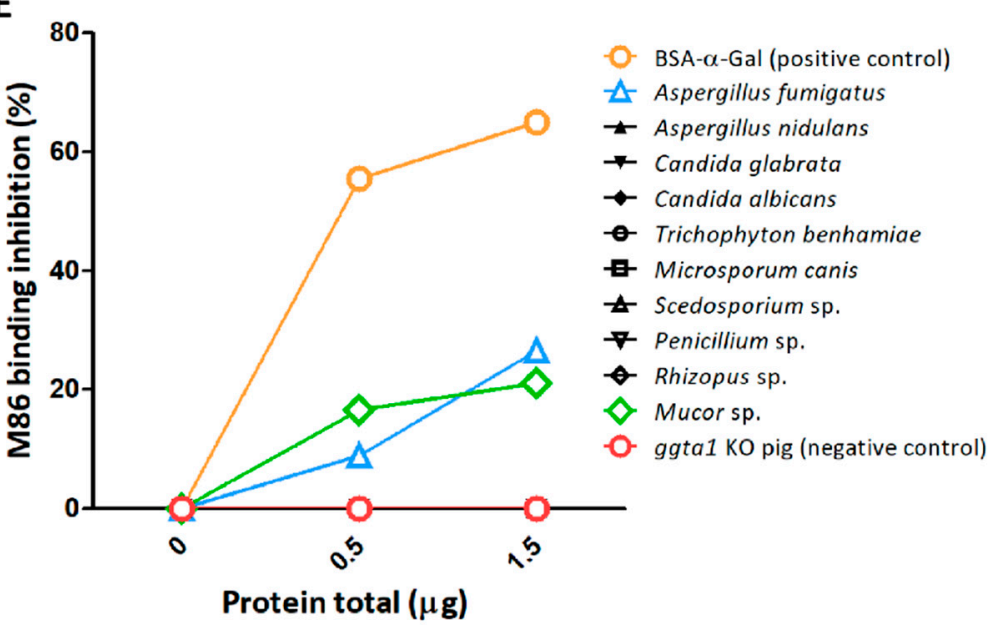

Figure 1. Detection of $\alpha$-Gal in A. fumigatus. The $\alpha$-Gal-specific mAb M86 (primary Ab) was used to detect the production of $\alpha$-Gal in A. fumigatus conidia (arrow heads) (A) and hyphae (B) by immunofluorescence. The mAb M86 was reactive to granular structures surrounding the hyphae (arrow heads) and the cytoplasm of hyphae cells (arrows) (B,C). Goat anti-mouse IgM-FITC was used as secondary $\mathrm{Ab}$ for detection of $\alpha$-Gal (green). Cell nuclei and mitochondria were stained with DAPI (blue) (A,B) and Mitotracker (red) (B), respectively. $\alpha$-Gal expression in conidia surface was measured by flow cytometry using M86 and Goat anti-mouse IgM-FITC. Mean and median fluorescence intensity (FI) values are presented. HL60 cells were used as a negative control (D). Presence of $\alpha$-Gal glycan in protein extract of Ascomycota (i.e., A. fumigatus, A. nidulans, C. glabrata, C. albicans, M. canis, Penicillium sp., Scedosporium sp., and T. benhamiae) and Zygomycota (i.e., Mucor sp. and Rhizopus sp.) fungi was measured by inhibition ELISA assay $(\mathbf{E})$.

3.2. Oral Administration of E. coli O86:B7 Reduces Clinical Signs of Aspergillosis and Development of Lung Granulomas in A. fumigatus-Infected Turkeys

Daily clinical examination of challenged birds revealed that oral administration of highly $\alpha$-Gal expressing E. coli O86:B7 protects the turkeys from developing respiratory clinical signs associated with avian aspergillosis such as open-mouthed breathing (OMB, Figure 2A), gasping and hyperpnea 
(Supplementary Video S1). This was not the case for PBS-treated (Figure 2A and Supplementary Video S2) nor E. coli BL21-treated (Figure 2A and Supplementary Video S3) turkeys. Four-days post-infection, all birds were sacrificed. Assessment of macroscopic lung lesions (Figure 2B) showed lungs of turkeys treated with PBS and E. coli BL21 with lesions suggesting granulomas that in some cases covered the whole organ (score 3, Figure 2B). This resulted in lesional scores significantly higher than those of E. coli O86:B7-treated animals in which granulomas were scarce (Figure 2C). Notably, only one turkey developed a small granuloma (score 1, Figure 2B) in the right lung. The scoring of histopathological lung lesions considered the level of inflammation and granulomas assessed by HES staining (HES score, Figure 2D) and the presence of hyphae assessed by PAS (PAS score, Figure 2E). Animals treated with E. coli O86:B7 had significant lower inflammation (Figure 2F) and hyphae (Figure 2G) scores than those treated with PBS and E. coli BL21. Lung samples were homogenized and applied either on agar for CFU counting assay or used for $28 S$ DNA quantification by qPCR. Despite a tendency of $A$. fumigatus CFU to decrease (Figure 2H) and 28S DNA levels to increase (Figure 2I) in the E. coli O86:B7-treated group, no significant differences were observed between groups. However, some animals in the E. coli O86:B7-treated group had 2-fold increase in the $28 \mathrm{~S}$ levels, possibly related to the presence of damaged fungal elements.

A

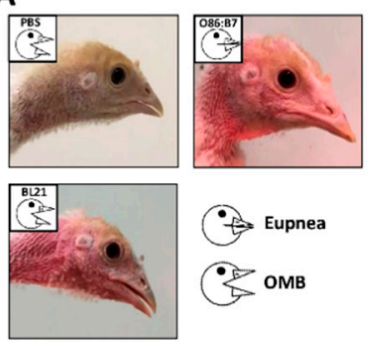

D
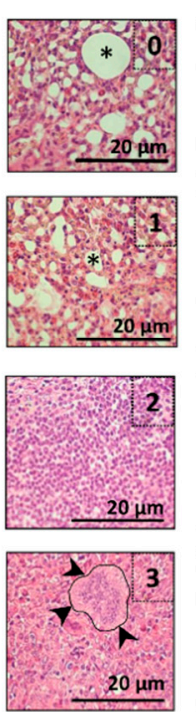

B
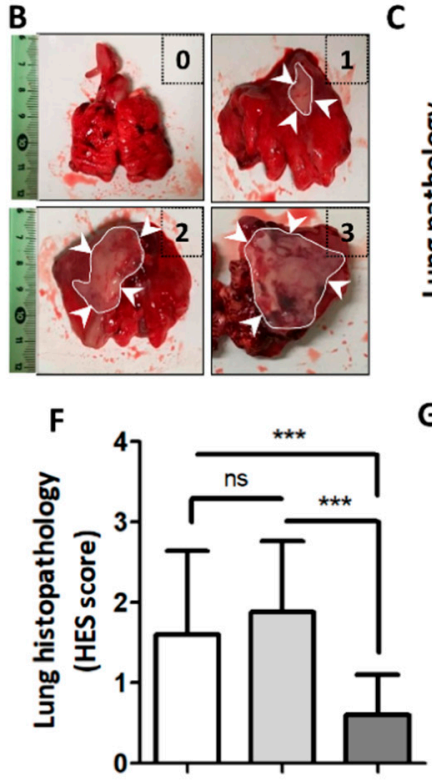

H

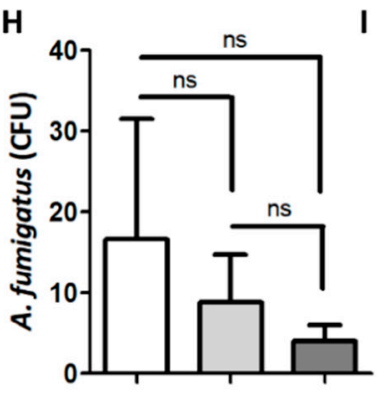

C

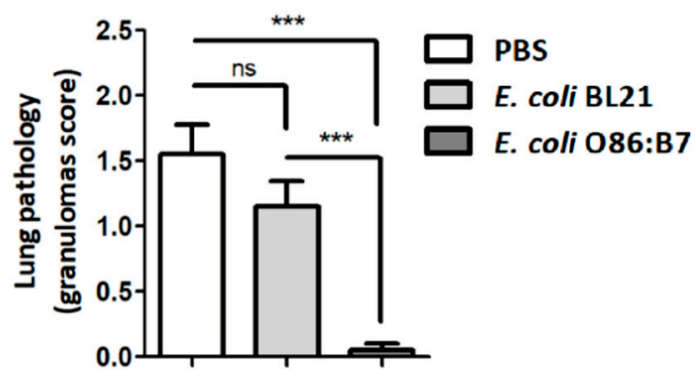

$\mathbf{G}$
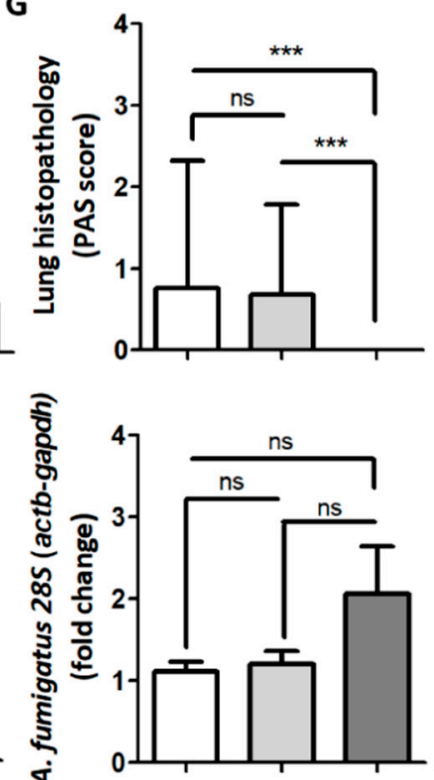

Figure 2. Oral administration of E. coli O86:B7 protects turkeys against aspergillosis. Clinical examination revealed that $A$. fumigatus infection produces open-mouthed breathing (OMB) in turkeys 
treated with PBS or E. coli BL21. Turkeys treated with E. coli O86:B7 were protected from developing OMB (A). Pulmonary lesions (i.e., granulomas, delimited area and white arrow heads) were scored (see methods). Examples of lungs with scores 0 to 3 are shown (B). Granuloma score was lower in turkeys treated with E. coli O86:B7 (C). Lung samples were processed for histopathology and stained with hematoxylin-eosin-saffron (HES, D) and periodic acid-schiff (PAS, E). Histological lesions were scored (see methods). Examples of histopathology samples with scores 0 to 3 are shown. Visible peribronchial regions (asterisk) and granulomas (delimited area and black arrow heads) are shown (HES score, D). The presence of fungal germ-tube/hyphae (black arrows) and mycelium (white arrows) was scored (see methods). Granulomas associated with fungal hyphae (delimited area and black arrow heads) are shown (PAS score, E). HES and PAS scores were lower in turkeys treated with E. coli O86:B7 (F,G). The presence of viable Aspergillus in lungs was quantified by colony-forming unit (CFU) counting assay (H). Fungal DNA levels were measured by A. fumigatus-specific $28 S$ qPCR normalizing against turkey $a c t b$ and gapdh as host genes using the $2^{-\Delta \Delta C t}$ ratio method. Results are relative to $28 S$ levels in the control group (i.e., PBS) (I). No significant change was observed in the amount of CFU and $28 S$ fold change (H,I). Size of bars is indicated. 100X magnification. Results shown are means and standard deviation values. Results were compared by One-way ANOVA with Dunnett's multiple comparison test applied for individual comparisons ( ${ }^{* * *} p<0.0001$; ns: not significant, 2 experiments, $n=30$ ).

3.3. Oral Administration of E. coli O86:B7 Decreases Anti- $\alpha$-Gal IgA Production in the Lungs of A. fumigatus-Infected Turkeys

Natural Abs have affinity for different $\alpha$-Gal-related antigens, including Gal $\alpha 1-3 \mathrm{Gal}$ disaccharide and Gal $\alpha 1-3$ Gal $\beta 1-4$ GlcNAc trisaccharide. Sera levels of immunoglobulin Y (IgY) and IgA against Gal $\alpha 1-3 \mathrm{Gal}$ and Gal $\alpha 1-3 \mathrm{Gal} \beta 1-4 \mathrm{GlcNAc}$ were measured by ELISA in sera from turkey that received PBS only. The levels of circulating IgY against Gal $\alpha 1-3 \mathrm{Gal}$ did not change over time (Supplementary Figure S1A), while the levels of anti-Gal $\alpha 1-3 \mathrm{Gal} \beta 1-4 \mathrm{GlcNAc}$ IgY significantly increased at day 31 (Supplementary Figure S1B). Only residual levels of circulating IgA against Gal $\alpha 1-3 \mathrm{Gal}$ were detected, and the level of these Abs did not changed over time (Supplementary Figure S1C).

Turkeys that received E. coli O86:B7 or E. coli BL21 orally showed no change in the levels of circulating IgY against Gal $\alpha 1-3 \mathrm{Gal}$, and only those treated with E. coli O86:B7 showed higher levels of circulating IgY against Gal $\alpha 1-3 \mathrm{Gal} \beta 1-4 \mathrm{GlcNAc}$ at day 7. The turkeys that received E. coli O86:B7 showed lower levels of circulating IgY against Gal $\alpha 1-3 \mathrm{Gal}$ at day 14 than turkeys that received PBS (Figure 3A), an effect not observed in turkeys that received E. coli BL21. At day 31, anti-Gal $\alpha 1-3 \mathrm{Gal}$ IgY levels were higher in animals that received E. coli O86:B7 and E. coli BL21, compared with animals that received PBS. However, turkeys treated with E. coli O86:B7 showed lower levels of anti-Gal $\alpha 1-3 \mathrm{Gal} \beta 1-4 \mathrm{GlcNAc}$ IgY at day 31 than animals that received E. coli BL21 or PBS (Figure 3B).

The specificity of the reactivity of turkey sera to Gal $\alpha 1-3 \mathrm{Gal}$ was tested by enzymatic removal of terminal $\alpha$-Gal residues from Gal $\alpha 1-3 \mathrm{Gal}-\mathrm{HSA}$. A significant decrease in the sera reactivity after the enzymatic removal of terminal $\alpha$-Gal residues from Gal $\alpha 1-3 \mathrm{Gal}-\mathrm{HSA}$ antigen was observed in turkeys from all groups (Supplementary Figure S2).

Lung proteins obtained from lung samples at day 31 (four days after infection) allowed the detection of IgA against Gal $\alpha 1-3 \mathrm{Gal}$ and Gal $\alpha 1-3 \mathrm{Gal} \beta 1-4 \mathrm{GlcNAc}$ by ELISA. Only residual levels of anti-Gal $\alpha 1-3 \mathrm{Gal}$ and anti-Gal $\alpha 1-3 \mathrm{Gal} \beta 1-4 \mathrm{GlcNAc}$ IgA Abs were detected in the lungs of turkeys that received E. coli O86:B7 (Figure 4A). This was not the case for E. coli BL21-treated or PBS-treated turkeys (Figure 4A). Positive correlations between the levels of anti-Gal $\alpha 1-3 \mathrm{Gal}$ or anti-Gal $\alpha 1-3 \mathrm{Gal} \beta 1-4 \mathrm{GlcNAc}$ $\operatorname{IgA}$ and the granulomas score in the lungs were found (Figure 4B). There was no correlation between levels of anti-Gal $\alpha 1-3 \mathrm{Gal}$ and anti-Gal $\alpha 1-3 \mathrm{Gal} \beta 1-4 \mathrm{GlcNAc}$ IgY and normalized A. fumigatus $28 S$ gene levels. 

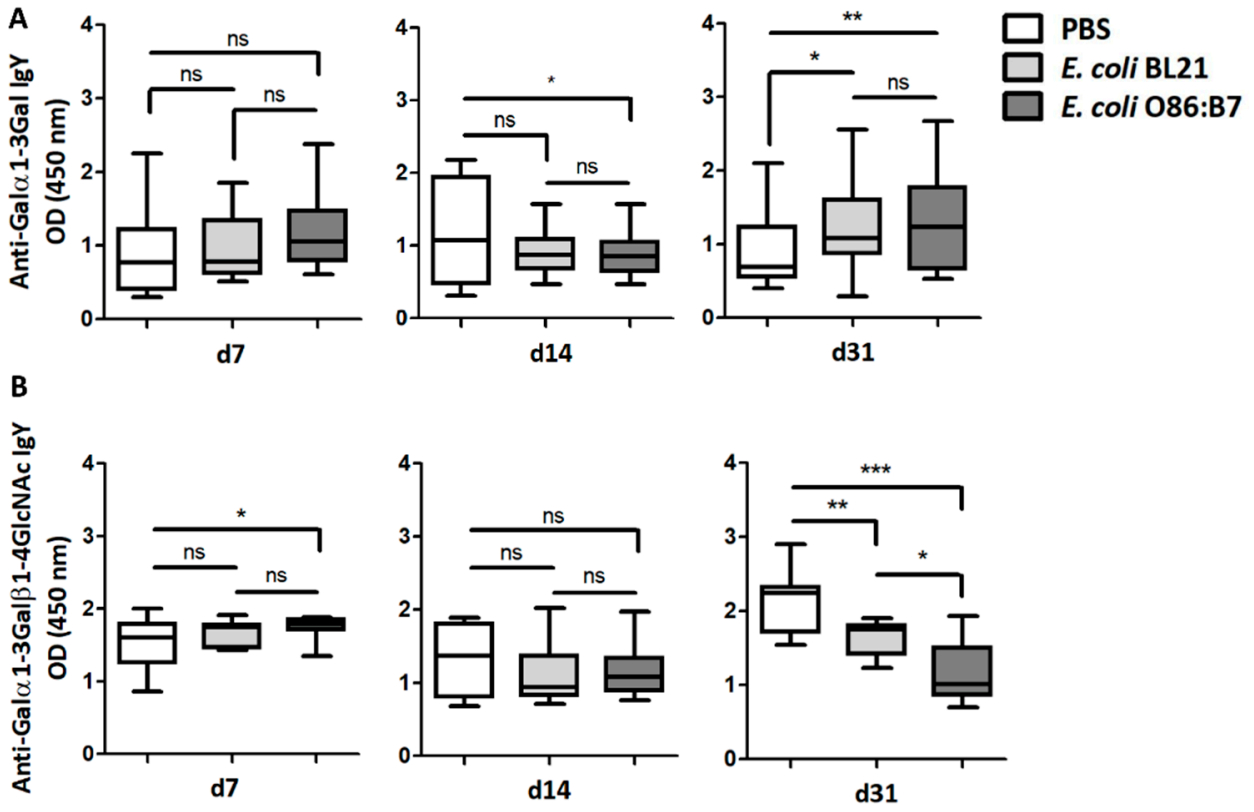

Figure 3. Oral administration of E. coli O86:B7 induces a significant decrease in the levels of anti-Gal $\alpha 1-3 \mathrm{Gal} \beta 1-4 \mathrm{GlcN} A c$ IgY Abs in A. fumigatus-infected turkeys. The levels of circulating anti- $\alpha$-Gal IgY Abs to Gal $\alpha 1-3 \mathrm{Gal}$ (A) and Gal $\alpha 1-3 \mathrm{Gal} \beta 1-4 \mathrm{GlcNAc}(\mathbf{B})$ were measured by ELISA. Anti-Gal $\alpha 1-3 \mathrm{Gal}$ IgY Abs increased in the sera of turkeys treated with E. coli O86:B7 and E. coli BL21. Oral administration of $E$. coli O86:B7 produces a significant reduction in anti-Gal $\alpha 1-3 \mathrm{Gal} \beta 1-4 \mathrm{GlcNAc}$ IgY Abs when compared with turkeys that were treated or not E. coli BL21. Results shown are means and standard deviation values. Results were compared by One-way ANOVA with Dunnett's multiple comparison test applied for individual comparisons $\left({ }^{*} p<0.05,{ }^{* *} p<0.001,{ }^{* * *} p<0.0001\right.$; ns: not significant, 2 experiments, $n=30$ and three technical replicates per sample).
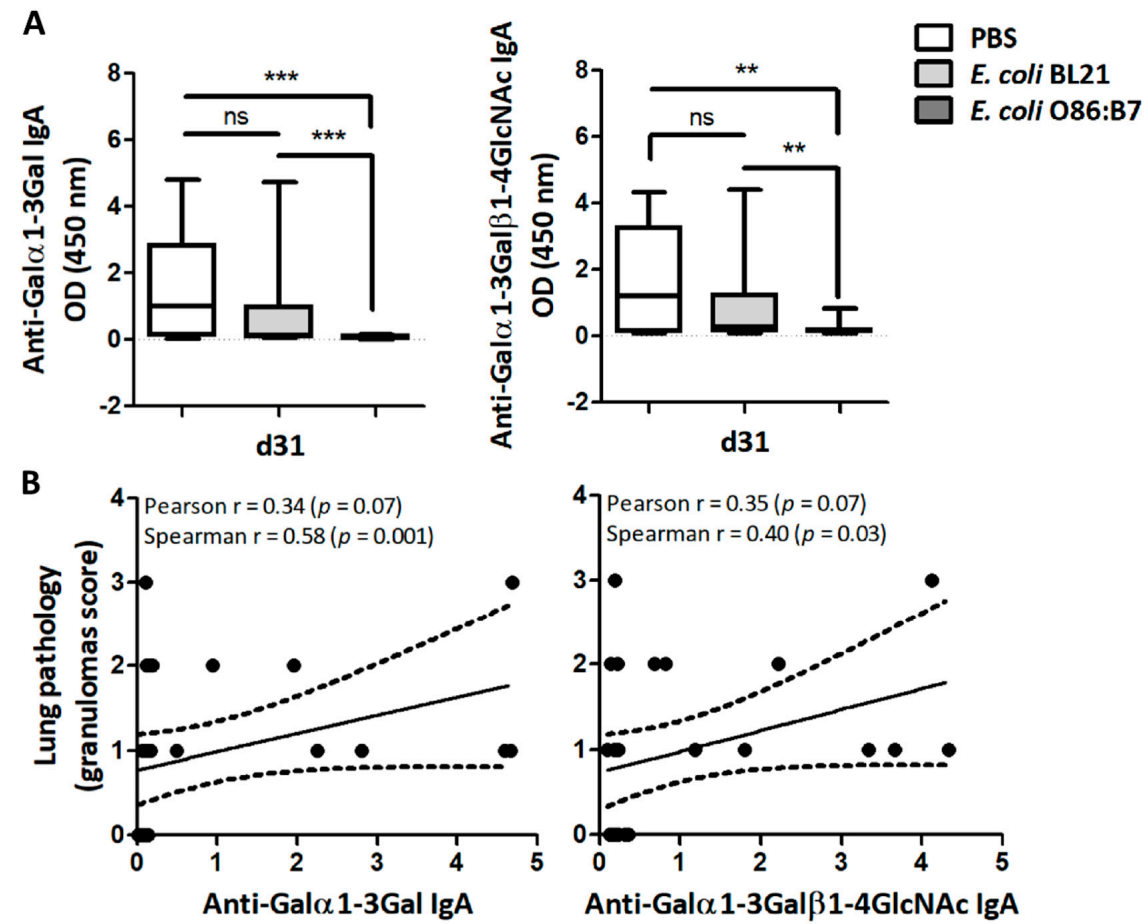

Figure 4. Oral administration of E. coli O86:B7 decreases the levels of anti- $\alpha-\mathrm{Gal}$ IgA Abs which correlates with lung pathology in A. fumigatus-infected turkeys. The levels of IgA against $\alpha$-Gal, Gal $\alpha 1-3 \mathrm{Gal}$ and Gal $\alpha 1-3 \mathrm{Gal} \beta 1-4 \mathrm{GlcNAc}$ in lungs of $A$. fumigatus-infected turkeys were measured by 
ELISA. The levels of anti- $\alpha$-Gal IgA between groups were compared by one-way ANOVA with Dunnett's multiple comparison test applied for individual comparisons ${ }^{* *} p<0.001,{ }^{* * *} p<0.0001$; ns: not significant, 2 experiments, $n=30$ and three technical replicates per sample) (A). Correlation between the levels of anti-Gal $\alpha 1-3 \mathrm{Gal}$ and anti-Gal $\alpha 1-3 \mathrm{Gal} \beta 1-4 \mathrm{GlcNAc}$ IgA and granuloma scores of turkeys treated with PBS, E. coli O86:B7 and E. coli BL21. Pearson and Spearman coefficients $r$ and $p$ values are indicated $(\mathbf{B})$.

\subsection{Immunization against Gala1-3Gal Increases Fungal Development in the Lungs}

Four days after infection, infected PBS-immunized turkeys developed significantly more lung granulomas (Figure 5A) and higher CFU (Figure 5B) when compared with chickens.

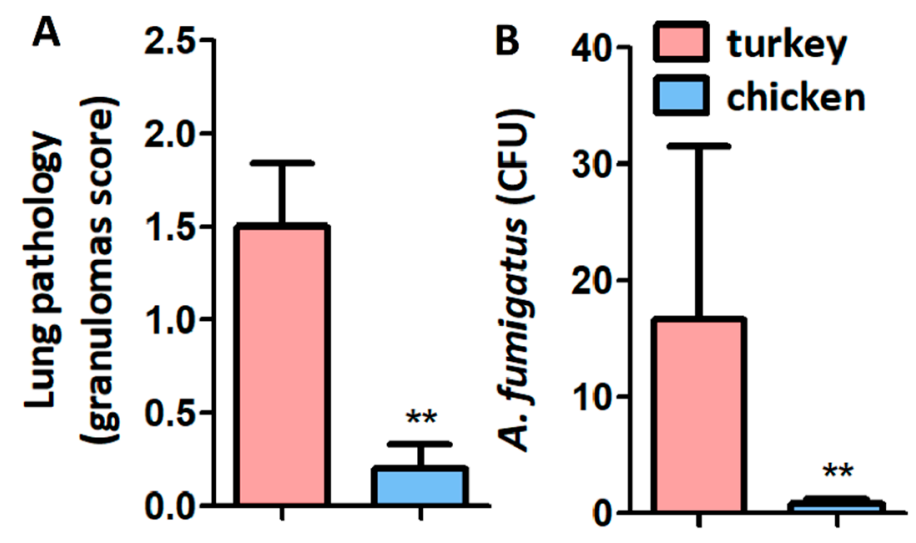

Figure 5. Granuloma score and CFU in turkeys and chickens infected with A. fumigatus. Lung granuloma score (A) and CFU counting (B) were lower in chicken than in turkeys (A). Results shown are means and standard deviation values. Results were compared by Mann-Whitney U test $(* * p 0.001$; 1 experiment with chickens, $n=5$ and 2 experiments with turkeys, $n=10$ ).

Immunization of turkeys using synthetic Gal $\alpha 1-3 \mathrm{Gal}$ conjugated to BSA ( $\alpha-\mathrm{Gal}-\mathrm{BSA})$, elicited the production of circulating IgY with affinity for Gal $\alpha 1-3 \mathrm{Gal}$ (Figure 6A and Supplementary Figure S3A). This $\mathrm{Ab}$ production was not associated with a significant change in the granulomas score (Figure 6B), and despite a tendency to increase, no significant difference was observed in the CFU number between the $\alpha$-Gal-BSA-immunized group and the control group (Figure 6C). Furthermore, the normalized levels of A. fumigatus $28 S$ were significantly higher in the lungs of turkeys immunized with $\alpha$-Gal-BSA (Figure 6D), compared with the control group. No significant changes were observed in IgY production against Gal $\alpha 1-3 \mathrm{Gal} \beta 1-4 \mathrm{GlcNAc}$ (Supplementary Figure S3B), in the levels of serum anti-Gal $\alpha 1-3 \mathrm{Gal}$ IgA (Supplementary Figure S3C), in the lung levels of anti-Gal $\alpha 1-3 \mathrm{Gal} \beta 1-4 \mathrm{GlcNAc}$ IgA (Supplementary Figure S3D) or of anti-Gal $\alpha 1-3 \mathrm{Gal}$ IgA Abs (Supplementary Figure S3E).

In chickens, $\alpha$-Gal-BSA immunization also elicited a significant increase in circulating anti-Gal $\alpha 1-3 \mathrm{Gal}$ IgY Abs (Figure $6 \mathrm{E}$ and Supplementary Figure S3F) and circulating anti-Gal $\alpha 1-3 \mathrm{Gal}$ IgA Abs in immunized chicken remained similar to the control group (Supplementary Figure S3G). Of the five chickens immunized with $\alpha$-Gal-BSA, four developed granulomas, two in the right and left lungs and two in the left lung only. In contrast, one animal of the control group developed granulomas in the right and left lungs. Despite a tendency to increase, no significant difference was observed in the granulomas score (Figure 6F), nor in the CFU number (Figure 6G), between the $\alpha$-Gal-BSA-immunized group and the control group. Notably, as per turkeys (Figure 6D), immunized chickens had a significant increase in the levels of A. fumigatus $28 \mathrm{~S}$ in lungs (Figure $6 \mathrm{H}$ ). 

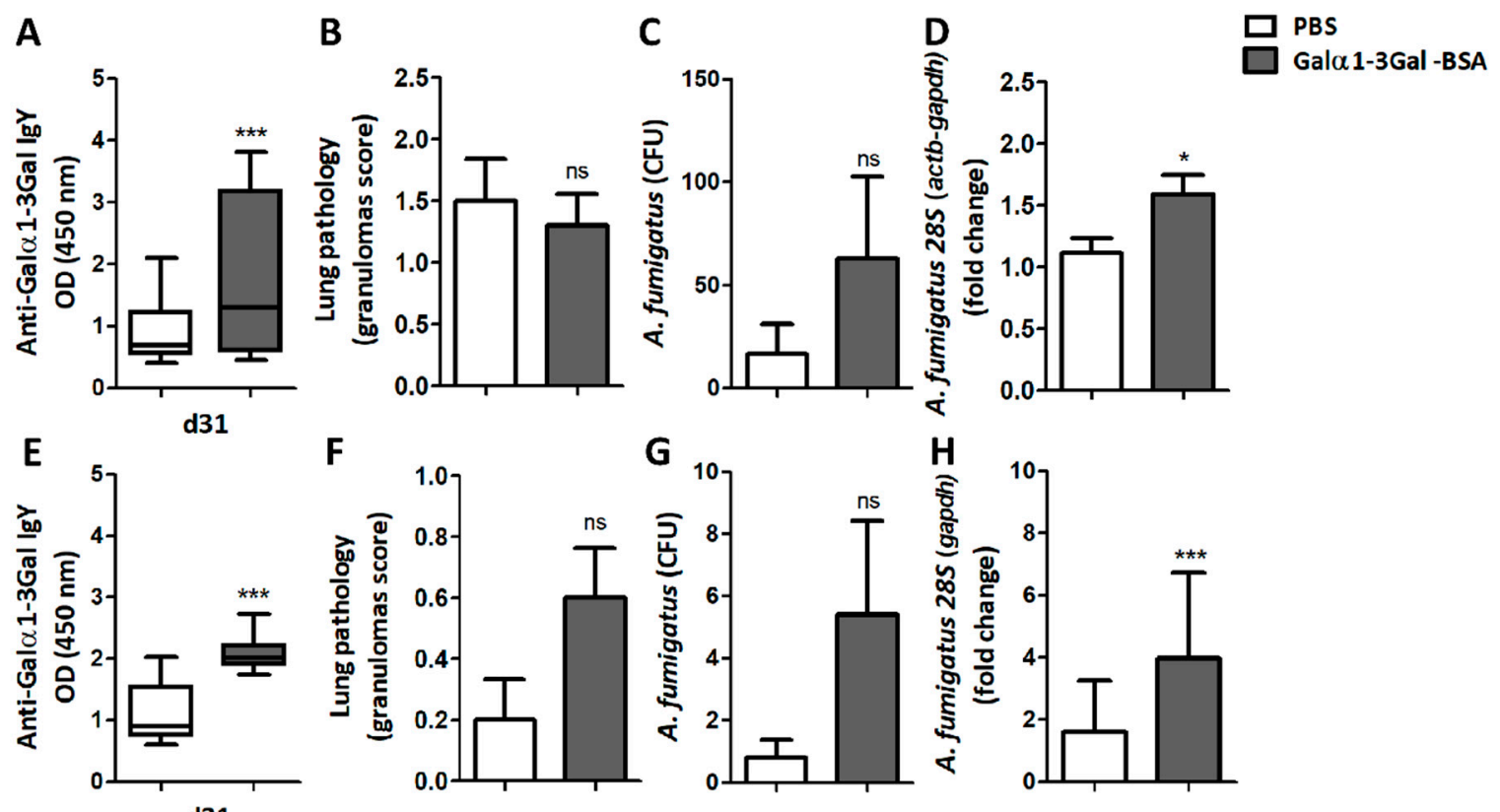

Figure 6. Immunization against $\alpha$-Gal-BSA increases fungal burden in turkeys and chickens. The levels of circulating anti- $\alpha-\mathrm{Gal}$ IgY Abs to Gal $\alpha 1-3 \mathrm{Gal}$, lung granuloma score and A. fumigatus CFU number and $28 S$ levels in lungs, were quantified in turkeys (A-D) and chickens (E-H). Immunization against $\alpha$-Gal-BSA increases the levels of anti- $\alpha$-Gal IgY Abs to Gal $\alpha 1-3 \mathrm{Gal}$ and A. fumigatus $28 S$ levels in turkeys (A,D) and chicken $(\mathbf{E}, \mathbf{H})$. Results shown are means and standard deviation values. Results were compared by unpaired non-parametric Mann-Whitney U test $\left({ }^{*} p<0.0001\right.$, ${ }^{* * *} p<0.0001$; ns: not significant, 1 experiment with chicken, $n=10$ and 2 experiments with turkeys, $n=20$ and three technical replicates per sample in the ELISA $(\mathbf{A}, \mathbf{B})$ and $q P C R(\mathbf{D}, \mathbf{H})$ assays).

3.5. Immunization against Gal 1-3Gal Is Associated with Upregulation of Pro-Inflammatory Cytokine Genes in A. fumigatus-Infected Turkeys and Chickens

We wondered whether oral administration of E. coli O86:B7 has an effect on the expression of genes encoding for pro-inflammatory (i.e., IFN $\gamma$, IL6, IL2) and anti-inflammatory (i.e., IL10) cytokines, as well as on the expression of innate immune receptor genes (i.e., MyD88) in the ceca and lungs of A. fumigatus-infected turkeys. MyD88 transcription was also assessed in turkeys treated with E. coli BL21 or immunized with $\alpha$-Gal-BSA. The effect of $\alpha$-Gal-BSA immunization on the expression of pro-inflammatory cytokines (i.e., IL6 and IL2) and of MyD88 adaptor in the lungs of $A$. fumigatus-infected chicken was also tested.

After cDNA normalization with the PBS control group, MyD88, IFN $\gamma$ and IL6 expression was significantly upregulated in the ceca of $\alpha$-Gal-BSA-immunized turkeys (Figure 7A). $\alpha$-Gal-BSA immunization also induced a significant upregulation of IL2 in turkey (Figure 7B) and chicken lungs and IL6 only in chicken lungs (Figure 7C). The oral administration of E. coli BL21 in turkeys was associated with the upregulation of IL10, IFN $\gamma$ and IL6 expression in ceca (Figure 7A) and IL6 expression in lungs (Figure 7B). Notably, except for IL2 for which a 27.8-fold increase was observed in ceca (Figure 7A), oral administration of E. coli O86:B7 was not associated with significant changes in the mRNA levels of the tested genes (Figure 7A,B). 
A
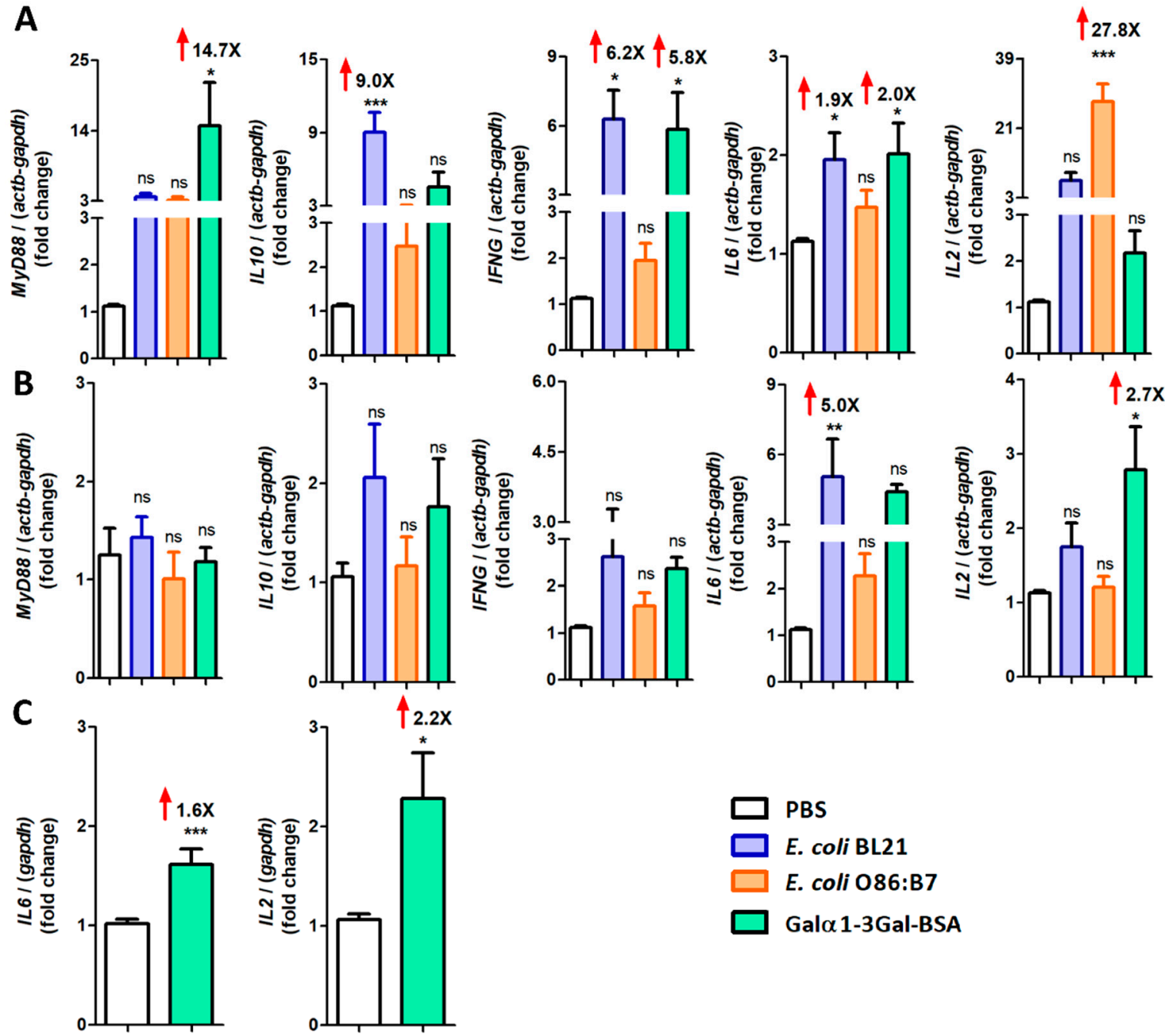

Figure 7. Expression of turkey and chicken cytokine genes in response to oral administration of E. coli O86:B7 and E. coli BL21 and $\alpha$-Gal-BSA immunization. The figure displays the mRNA expression levels of INF $\gamma$, IL6, IL2, IL10 and MyD88 in ceca (A) and lungs (B) of turkeys and IL6 and IL2 in lungs of chicken (C). Total RNA was extracted and gene expression levels were measured by qPCR normalizing against turkey $a c t b$ and gapdh as housekeeping genes, using the using the $2^{-\Delta \Delta C t}$ ratio method. Expression levels are relative to the control group (i.e., PBS). Results shown are means and standard deviation values. Results were compared by One-way ANOVA with Dunnett's multiple comparison test applied for individual comparisons $\left({ }^{*} p<0.0001,{ }^{* *} p<0.001,{ }^{* * *} p<0.0001\right.$; ns: not significant, the magnitude of significant fold changes compared with the PBS are shown (red arrows), 1 experiment with chicken, $n=10$ and 2 experiments with turkeys, $n=40$ and three technical replicates per sample).

\section{Discussion}

Evidence for the protective role of gut microbiota against pathogens expressing $\alpha$-Gal on their surface was initially provided by Yilmaz et al. (2014) [8], who showed that gut colonization by E. coli O86:B7 expressing high levels of $\alpha$-Gal elicited the production of anti- $\alpha$-Gal IgM Abs that protected $\alpha$-Gal-deficient mice against malaria transmission by Anopheles mosquitoes. In the present study, we extend these initial observations by showing that the oral administration of E. coli O86:B7 protects non-mammalian vertebrates against a fungal pathogen expressing $\alpha$-Gal on its surface. In our model, oral administration of E. coli O86:B7 protected turkeys from developing clinical and lesional aspergillosis. However, in contrast with the results by Yilmaz et al. (2014) [8], the protective effect of E. coli O86:B7 was not associated with an increase in the levels of anti- $\alpha$-Gal Abs, but with a significant 
reduction in the levels of circulating IgY Abs with reactivity to Gal $\alpha 1-3 \mathrm{Gal} \beta 1-4 \mathrm{GlcNAc}$ and IgA Abs with reactivity to Gal $\alpha 1-3 \mathrm{Gal} \beta 1-4 \mathrm{GlcNAc}$ and Gal $\alpha 1-3 \mathrm{Gal}$ in the lungs of A. fumigatus-infected animals. It is noteworthy that Yilmaz et al. (2014) [8] administered E. coli O86:B7 ( 107 CFU) 3 times at two weeks intervals, while we used three consecutive administrations of E. coli O86:B7 ( 1 10 $\mathrm{CFU}$ ) repeated three times at four-day intervals. Our results suggest that the continuous administration of large doses of highly $\alpha$-Gal expressing E. coli O86:B7 decreased or totally abrogated responsiveness to the $\alpha$-Gal on the surface of $A$. fumigatus. Intestinal microbiota has profound effects on the gut immune system and the induction and maintenance of oral and systemic tolerance [40-42]. For example, oral administration of Lactococcus lactis engineered to secrete deamidated DQ8 gliadin epitope or ovalbumin (OVA) induced suppression of local and systemic responses to these antigens $[43,44]$. Likewise, intestinal colonization of mice with non-pathogenic E. coli expressing OVA on the surface induced the expansion of antigen-specific regulatory $\mathrm{T}$ cells (Tregs) and mediated systemic immune tolerance [45]. A population of Tregs with suppressive properties similar to that of mammalian Tregs was described in turkeys, chickens and ducks [46-48]. These avian Tregs can migrate and be resident in cecum and lung tissues $[46,48]$. Among the regulatory functions of Tregs is the suppression of production of antigen-specific Abs [49]. Further studies should address whether the decreased of anti- $\alpha$-Gal Abs in response to A. fumigatus infection is caused by the induction of $\alpha$-Gal-specific Tregs in $E$. coli O86:B7-treated turkeys.

Interaction between host anti- $\alpha$-Gal Abs and pathogens expressing $\alpha$-Gal might play a role in benefit of pathogen survival, as shown for the blood isolate \#21 of Serratia marcescens, where binding of anti- $\alpha$-Gal Abs to the bacterial lipopolysaccharide (LPS) blocked alternative complement pathway (ACP)-mediated lysis of the bacteria [50]. Likewise, depletion of inhibitory serum anti- $\alpha-G a l$ Abs by a soluble trisaccharide-polylysine conjugate (commercial name RA-01, www.remabtx.com) protected patients from multidrug-resistant Gram-negative bacteria, including E. coli, Pseudomonas aeruginosa, and Klebsiella pneumonia expressing $\alpha$-Gal [50-52]. In the present study, A. fumigatus was the sole Ascomycota expressing $\alpha$-Gal. Aspergillus fumigatus conidia is susceptible to ACP activation [53]. Therefore, the synthesis of $\alpha$-Gal and binding of anti- $\alpha$-Gal Abs on the surface of A. fumigatus may be an ultimate fungal strategy for ACP evasion in animals lacking endogenous $\alpha$-Gal and capable of producing inhibitory natural anti- $\alpha$-Gal Abs. The increase of $A$. fumigatus levels after $\alpha$-Gal-BSA immunization in turkeys and chickens supports a role of circulating anti-Gal $\alpha 1-3 \mathrm{Gal} \operatorname{IgY}$ Abs in promoting fungal development, by a mechanism that remains to be elucidated, but likely involving the inhibition of ACP activation.

Our results showed a positive correlation between the levels of anti-Gal $\alpha 1-3 \mathrm{Gal} \beta 1-4 \mathrm{GlcN} A c$ and anti-Gal $\alpha 1-3 \mathrm{Gal}$ IgA and the occurrence and development of granulomas in the lungs of A. fumigatus-infected turkeys, suggesting a pro-inflammatory role of anti- $\alpha$-Gal IgA. To further evaluate the role of anti- $\alpha-G a l$ Abs in aspergillosis, we took advantage of the availability of susceptible and tolerant models of avian aspergillosis. Vulnerability to this fungal infection varies among bird species, with turkeys having the highest susceptibility when compared to chickens $[30,33,34]$. The results confirmed that $\alpha$-Gal immunization increased the number of granulomas in chickens and the fungal burden in chickens and turkeys. B cells and antibodies are required for granuloma formation in early infection by Schistosoma japonicum [54] and Mycobacterium tuberculosis [55-57]. Granuloma plays a role as an immune and physical barrier and is crucial in preventing pathogen dissemination within the host [58]. However, within the granulomatous lesion, the pathogen is protected from total clearance by the immune system $[58,59]$, and, as observed in the present study, granulomas can be harmful to the host physiology by decreasing lung capacity. Respiratory impairment due to lung granulomas in aspergillosis can be lethal in turkeys [30]. Disease tolerance is the reduction of the negative impact of an infection on host fitness without directly affecting the pathogen burden $[60,61]$. Anti- $\alpha$-Gal Abs are immune mediators of inflammation that activate the complement and macrophages, and induce NK cell recruitment and endothelial cell activation [51,62,63]. Oral administration of E. coli O86:B7 reduced the occurrence and severity of lung granulomas, with no effect in the fungal burden, 
suggesting a mechanism in which gut microbiota promotes disease tolerance in the lungs by preventing the upregulation of pro-inflammatory cytokines (i.e., IL2, IL6 and INF $\gamma$ ) and by decreasing the levels of anti- $\alpha-\mathrm{Gal}$ Abs in response to A. fumigatus infection.

Previous studies showed that $\alpha-$ Gal immunization elicits an anti- $\alpha-G a l$ Abs response that protects $\alpha$-Gal-deficient mice against Trypanosoma cruzi [64,65], Leishmania spp. [66], and Plasmodium spp. [8], and zebrafish against mycobacteria [67]. The study by Yilmaz et al., 2014 [8] showed that the protective role of anti- $\alpha-G a l$ Abs against malaria was not observed when Plasmodium sporozoites were inoculated intravenously, suggesting that the protective effect of $\alpha$-gal immunization was only exerted when the pathogen was delivered in the dermis by mosquito bites. In addition, $\alpha$-Gal immunization protected $\alpha$-Gal-deficient mice against intraperitoneal infection with Leishmania infantum, subcutaneous infection with L. amazonensis [66] or intraperitoneal infection with Trypanosoma cruzi [65]. Based on this evidence, the use of $\alpha$-Gal in a single-antigen pan vaccine to control major infectious diseases caused by pathogens expressing $\alpha$-Gal on their surface was proposed [68,69]. Here, however, we showed that $\alpha$-Gal immunization elicits an $\alpha$-Gal-specific IgY response that did not protect chickens or turkeys against an intratracheal challenge with $A$. fumigatus. In addition, anti- $\alpha-\mathrm{Gal}$ IgA seems to be involved in the formation and development of granulomas in birds. In contrast, $\alpha-$ Gal immunization reduced the mean number of tuberculous granuloma lesions in zebrafish infected with Mycobacterium marinum intraperitoneally [67]. However, the reduction of tuberculous granuloma was no longer observed when zebrafish were infected by mucosal M. marinum [67]. These studies suggest that the protective effect of $\alpha$-Gal immunization varies with the route of pathogen infection.

\section{Conclusions}

In the present study, we showed that gut microbiota bacteria expressing high levels of $\alpha$-Gal protect turkeys against aspergillosis. Continuous administration of E. coli O86:B7 abrogated the anti- $\alpha-\mathrm{Gal} \operatorname{IgA}$ response in the lungs of turkeys infected by $A$. fumigatus, a pathogen containing $\alpha$-Gal on the surface. The absence of lung lesions in turkeys treated with E. coli O86:B7 and infected with A. fumigatus suggests that anti- $\alpha$-Gal IgA are pro-inflammatory Abs that enhance the occurrence and development of lung lesions associated with acute aspergillosis. The mechanism by which gut microbiota abrogates anti- $\alpha$-Gal IgA response in the lungs remains to be elucidated, but we hypothesized that it involves the generation of $\alpha$-Gal-specific Tregs in the guts, which can then migrate to the lungs and induce tolerance to the A. fumigatus $\alpha$-Gal. The absence of lung lesions allowed the animals to tolerate the fungal infection with no clinical signs, which suggests the possibility of using gut microbiota bacteria expressing high levels of $\alpha$-Gal to prevent acute aspergillosis in animals and humans. We concluded that the increase in the level of circulating IgY against Gal $\alpha 1-3 \mathrm{Gal}$ after $\alpha$-Gal-immunization, together with the presence of anti- $\alpha-\mathrm{Gal}$ IgA Abs in the lungs, enhances the fungal burden, and the occurrence of granulomas in the lungs of infected chicken. The results of this study support the use of $\alpha$-Gal expressing probiotic-based vaccines to modulate the $\alpha$-Gal immunity [70], without the potential negative effects associated with other conventional vaccines using $\alpha$-Gal as antigen. We hypothesized that a probiotic-based vaccine containing high levels of $\alpha$-Gal would boost the levels of circulating anti- $\alpha$-Gal IgM and/or IgG [8], which are protective against Plasmodium spp. [8], T. cruzi [65,66], Leishmania spp. [66], mycobacteria [68] and potentially other pathogens expressing $\alpha-G a l$. At the same time, this $\alpha$-Gal-probiotic-based vaccine would abrogate the anti- $\alpha$-Gal IgA response in the lungs, which could then induce tolerance to diseases, such as aspergillosis and tuberculosis associated with the formation of granulomas.

Supplementary Materials: The following are available online at http://www.mdpi.com/2076-393X/8/2/285/s1, Figure S1: Levels of circulating IgY against Gal $\alpha 1-3 \mathrm{Gal}(\mathrm{A})$, circulating IgY against Gal $\alpha 1-3 \mathrm{Gal} \beta 1-4 \mathrm{GlcNAc}$ (B) and circulating IgA against Gal $\alpha 1-3 \mathrm{Gal}(\mathrm{C})$ were measured by indirect ELISA in control turkeys treated with PBS, Figure S2: The specificity of turkey anti- $\alpha$-Gal Abs was tested by indirect ELISA in animals treated with PBS, E. coli BL21 and E. coli O86:B7. In comparison with the untreated group, a reduction in reactivity against Gal $\alpha 1-3 \mathrm{Gal}-\mathrm{HSA}$ was observed after the antigen was pretreated with $\alpha$-galactosidase, Figure S3: Levels of circulating IgY against Gal $\alpha 1-3$ Gal (A), circulating IgY against Gal $\alpha 1-3 \mathrm{Gal} \beta 1-4 \mathrm{GlcNAc}(\mathrm{B})$ and circulating IgA against Gal $\alpha 1-3 \mathrm{Gal}(\mathrm{C})$ 
were measured in turkey sera by indirect ELISA in animals immunized with $\alpha$-Gal-BSA (Gal $\alpha 1-3 \mathrm{Gal}-\mathrm{BSA})$ or the mock vaccine (PBS). Levels of IgA against Gal $\alpha 1-3 \mathrm{Gal}(\mathrm{D})$, and Gal $\alpha 1-3 \mathrm{Gal} \beta 1-4 \mathrm{GlcNAc}(\mathrm{E})$ were measured in turkey lungs. Levels of circulating $\operatorname{IgY}(\mathrm{F})$ and circulating $\operatorname{Ig} A(\mathrm{G})$ against Gal $\alpha 1-3 \mathrm{Gal}$ were measured by indirect ELISA in sera of chickens immunized with $\alpha$-Gal-BSA (Gal $\alpha 1-3 \mathrm{Gal}-\mathrm{BSA})$ or the mock vaccine (PBS), Video S1: Video of turkey treated with E. coli O86:B7 and challenged with A. fumigatus. E. coli O86:B7 protects the turkeys from developing OMB, gasping and hyperpnea, Video S2: Video of control turkey treated with PBS and challenged with A. fumigatus. Turkeys in this group developed OMB, gasping and hyperpnea, Video S3: Video of turkey treated with E. coli BL21 and challenged with A. fumigatus. Turkeys in this group developed OMB, gasping and hyperpnea.

Author Contributions: Conceptualization, A.C.-C., J.G., V.R.-C., and J.d.1.F.; methodology, L.M.-H., V.R.-C., E.T.-M., and L.G.B.-H.; formal analysis, L.M.-H. and A.C.-C.; investigation, L.M.-H., V.R.-C., P.A., A.H., A.H.-J., S.R., C.G., and E.D.; resources, A.C.-C., J.G., V.R.-C., and J.d.l.F.; writing-original draft preparation, A.C.-C., L.M.-H. and V.R.-C.; writing-review and editing, A.C.-C., L.M.-H., E.T.-M.,V.R.-C., J.G., L.G.B.-H., J.d.1.F., and A.H.; visualization, A.C.-C., and P.A.; supervision, V.R.-C., and A.C.-C. All authors have read and agreed to the published version of the manuscript.

Funding: This research received no external funding.

Acknowledgments: We thank members of our laboratories for fruitful discussions on this manuscript.

Conflicts of Interest: In the last 3 years, J.G. has received grants from Boehringer-Ingelheim, as well as payments for lectures from Boehringer-Ingelheim, MSD, Virbac and Gilead. None of these companies were involved in the study design, collection, analysis, interpretation of data, the writing of this article or the decision to submit it for publication. The rest of the authors declare no conflict of interest.

\section{References}

1. Galili, U.; Shohet, S.B.; Kobrin, E.; Stults, C.L.; Macher, B.A. Man, apes, and Old World monkeys differ from other mammals in the expression of $\alpha$-galactosyl epitopes on nucleated cells. J. Biol. Chem. 1988, 263, 17755-17762. [PubMed]

2. Galili, U.; Clark, M.R.; Shohet, S.B.; Buehler, J.; Macher, B.A. Evolutionary relationship between the natural anti-Gal antibody and the Gal $\alpha 1-3 G a l$ epitope in primates. Proc. Natl. Acad. Sci. USA 1987, 84, 1369-1373. [CrossRef]

3. Macher, B.A.; Galili, U. The Gal $\alpha 1$, 3Gal $\beta 1,4$ GlcNAc-R ( $\alpha$-Gal) epitope: A carbohydrate of unique evolution and clinical relevance. Biochim. Biophys. Acta 2008, 1780, 75-88. [CrossRef] [PubMed]

4. Galili, U.; Rachmilewitz, E.A.; Peleg, A.; Flechner, I. A unique natural human IgG antibody with anti- $\alpha$-galactosyl specificity. J. Exp. Med. 1984, 160, 1519-1531. [CrossRef] [PubMed]

5. Galili, U.; Mandrell, R.E.; Hamadeh, R.M.; Shohet, S.B.; Griffiss, J.M. Interaction between human natural anti- $\alpha$-galactosyl immunoglobulin $\mathrm{G}$ and bacteria of the human flora. Infect. Immun. 1988, 56, 1730-1737. [CrossRef]

6. Pal, S.C.; Rao, C.K.; Kereselidze, T.; Krishnaswami, A.K.; Murty, D.K.; Pandit, C.G.; Shrivastav, J.B. An extensive community outbreak of enteropathogenic Escherichia coli O86: B7 gastroenteritis. Bull. World Health Organ. 1969, 41, 851-858. [PubMed]

7. Cabezas-Cruz, A.; Mateos-Hernández, L.; Alberdi, P.; Villar, M.; Riveau, G.; Hermann, E.; Schacht, A.M.; Khalife, J.; Correia-Neves, M.; Gortazar, C.; et al. Effect of blood type on anti- $\alpha$-Gal immunity and the incidence of infectious diseases. Exp. Mol. Med. 2017, 49, e301. [CrossRef]

8. Yilmaz, B.; Portugal, S.; Tran, T.M.; Gozzelino, R.; Ramos, S.; Gomes, J.; Regalado, A.; Cowan, P.J.; d'Apice, A.J.; Chong, A.S.; et al. Gut microbiota elicits a protective immune response against malaria transmission. Cell 2014, 159, 1277-1289. [CrossRef]

9. Posekany, K.J.; Pittman, H.K.; Bradfield, J.F.; Haisch, C.E.; Verbanac, K.M. Induction of cytolytic anti-Gal antibodies in $\alpha$-1,3-galactosyltransferase gene knockout mice by oral inoculation with Escherichia coli O86:B7 bacteria. Infect. Immun. 2002, 70, 6215-6222. [CrossRef]

10. Mañez, R.; Blanco, F.J.; Díaz, I.; Centeno, A.; Lopez-Pelaez, E.; Hermida, M.; Davies, H.F.; Katopodis, A. Removal of bowel aerobic gram-negative bacteria is more effective than immunosuppression with cyclophosphamide and steroids to decrease natural $\alpha$-galactosyl IgG antibodie. Xenotransplantation 2001, 8, 15-23. [CrossRef]

11. Springer, G.F.; Horton, R.E.; Forbes, M. Origin of anti-human blood group B agglutinins in white Leghorn chicken. J. Exp. Med. 1959, 110, 221-244. [CrossRef] [PubMed] 
12. Springer, G.F.; Horton, R.E. Blood group isoantibody stimulation in man by feeding blood group-active bacteria. J. Clin. Investig. 1969, 48, 1280-1291. [CrossRef] [PubMed]

13. Cabezas-Cruz, A.; Hodžić, A.; Román-Carrasco, P.; Mateos-Hernández, L.; Duscher, G.G.; Sinha, D.K.; Hemmer, W.; Swoboda, I.; Estrada-Peña, A.; de la Fuente, J. Environmental and Molecular Drivers of the $\alpha$-Gal Syndrome. Front. Immunol. 2019, 10, 1210. [CrossRef] [PubMed]

14. Commins, S.P.; James, H.R.; Kelly, L.A.; Pochan, S.L.; Workman, L.J.; Perzanowski, M.S.; Kocan, K.M.; Fahy, J.V.; Nganga, L.W.; Ronmark, E.; et al. The relevance of tick bites to the production of IgE antibodies to the mammalian oligosaccharide galactose- $\alpha-1,3$-galactose. J. Allergy Clin. Immunol. 2011, 127, 1286-1293. [CrossRef]

15. Cabezas-Cruz, A.; Valdés, J.; de la Fuente, J. Cancer research meets tick vectors for infectious diseases. Lancet Infect. Dis. 2014, 14, 916-917. [CrossRef]

16. Steinke, J.W.; Platts-Mills, T.A.; Commins, S.P. The $\alpha$-gal story: Lessons learned from connecting the dots. J. Allergy Clin. Immunol. 2015, 135, 589-596. [CrossRef]

17. Mateos-Hernández, L.; Villar, M.; Moral, A.; Rodríguez, C.G.; Arias, T.A.; de la Osa, V.; Brito, F.F.; Fernández de Mera, I.G.; Alberdi, P.; Ruiz-Fons, F.; et al. Tick-host conflict: Immunoglobulin E antibodies to tick proteins in patients with anaphylaxis to tick bite. Oncotarget 2017, 8, 20630-20644. [CrossRef]

18. Hodžić, A.; Mateos-Hernández, L.; de la Fuente, J.; Cabezas-Cruz, A. Delayed hypersensitivity reaction to mammalian galactose- $\alpha-1,3$-galactose ( $\alpha$-Gal) after repeated tick bites in a patient from France. Ticks Tick Borne Dis. 2019, 10, 1057-1059. [CrossRef]

19. Kiewiet, M.B.G.; Apostolovic, D.; Starkhammar, M.; Grundström, J.; Hamsten, C.; van Hage, M. Clinical and Serological Characterization of the $\alpha$-Gal Syndrome-Importance of Atopy for Symptom Severity in a European Cohort. J. Allergy Clin. Immunol. Pract. 2020, 10, 2027-2034.e2. [CrossRef]

20. Cabezas-Cruz, A.; Espinosa, P.J.; Alberdi, P.; Šimo, L.; Valdés, J.J.; Mateos-Hernández, L.; Contreras, M.; Rayo, M.V.; de la Fuente, J. Tick galactosyltransferases are involved in $\alpha$-Gal synthesis and play a role during Anaplasma phagocytophilum infection and Ixodes scapularis tick vector development. Sci. Rep. 2018, 8, 14224. [CrossRef]

21. Crispell, G.; Commins, S.P.; Archer-Hartman, S.A.; Choudhary, S.; Dharmarajan, G.; Azadi, P.; Karim, S. Discovery of $\alpha$-Gal-Containing Antigens in North American Tick Species Believed to Induce Red Meat Allergy. Front. Immunol. 2019, 10, 1056. [CrossRef] [PubMed]

22. Villar, M.; Pacheco, I.; Merino, O.; Contreras, M.; Mateos-Hernández, L.; Prado, E.; Barros-Picanço, D.K.; Lima-Barbero, J.F.; Artigas-Jerónimo, S.; Alberdi, P.; et al. Tick and Host Derived Compounds Detected in the Cement Complex Substance. Biomolecules 2020, 10, 555. [CrossRef] [PubMed]

23. Park, Y.; Kim, D.; Boorgula, G.D.; De Schutter, K.; Smagghe, G.; Šimo, L.; Archer-Hartmann, S.A.; Azadi, P. $\alpha-$ Gal and Cross-Reactive Carbohydrate Determinants in the N-Glycans of Salivary Glands in the Lone Star Tick, Amblyomma americanum. Vaccines 2020, 8, 18. [CrossRef] [PubMed]

24. Hodžić, A.; Mateos-Hernández, L.; Fréalle, E.; Román-Carrasco, P.; Alberdi, P.; Pichavant, M.; Risco-Castillo, V.; Le Roux, D.; Vicogne, J.; Hemmer, W.; et al. Infection with Toxocara canis Inhibits the Production of IgE Antibodies to $\alpha$-Gal in Humans: Towards a Conceptual Framework of the Hygiene Hypothesis? Vaccines 2020, 8, 167. [CrossRef] [PubMed]

25. Latgé, J.P. Aspergillus fumigatus and aspergillosis. Clin. Microbiol. Rev. 1999, 12, 310-350. [CrossRef] [PubMed]

26. Arné, P.; Thierry, S.; Wang, D.; Deville, M.; Le Loc’h, G.; Desoutter, A.; Féménia, F.; Nieguitsila, A.; Huang, W.; Chermette, R.; et al. Aspergillus fumigatus in Poultry. Int. J. Microbiol. 2011, 746356.

27. Latgé, J.P.; Chamilos, G. Aspergillus fumigatus and Aspergillosis in 2019. Clin. Microbiol. Rev. 2019, 33, e00140-18. [CrossRef]

28. Beernaert, L.A.; Pasmans, F.; Van Waeyenberghe, L.; Haesebrouck, F.; Martel, A. Aspergillus infections in birds: A review. Avian Pathol. 2010, 39, 325-331. [CrossRef]

29. Discher, D.; Van Waeyenberghe, L.; Failing, K.; Martel, A.; Lierz, M. Single tracheal inoculation of Aspergillus fumigatus conidia induced aspergillosis in juvenile falcons (Falco spp.). Avian Pathol. 2018, 47, 33-46.

30. Melloul, E.; Thierry, S.; Durand, B.; Cordonnier, N.; Desoubeaux, G.; Chandenier, J.; Bostvironnois, C.; Botterel, F.; Chermette, R.; Guillot, J.; et al. Assessment of Aspergillus fumigatus burden in lungs of intratracheally-challenged turkeys (Meleagris gallopavo) by quantitative PCR, galactomannan enzyme immunoassay, and quantitative culture. Comp. Immunol. Microbiol. Infect. Dis. 2014, 37, 271-279. [CrossRef] 
31. Zhang, R.R.; Wang, S.F.; Lu, H.W.; Wang, Z.H.; Xu, X.L. Clinical in vestigation of misdiagnosis of invasive pulmonary aspergillosis in 26 immunocompetent patients. Int. J. Clin. Exp. Med. 2014, 7, 4139-4146. [PubMed]

32. Gonçalves, S.M.; Lagrou, K.; Duarte-Oliveira, C.; Maertens, J.A.; Cunha, C.; Carvalho, A. The microbiome-metabolome crosstalk in the pathogenesis of respiratory fungal diseases. Virulence 2017, 8 , 673-684. [CrossRef] [PubMed]

33. Ghori, H.M.; Edgar, S.A. Comparative susceptibility of chickens, turkeys and Coturnix quail to aspergillosis. Poult Sci. 1973, 52, 2311-2315. [CrossRef] [PubMed]

34. Kunkle, R.A. Aspergillosis. In Diseases of Poultry, 11th ed.; Saif, Y.M., Barnes, H.J., Glisson, J.R., Eds.; Iowa State University Press: Ames, IA, USA, 2003; pp. 883-895.

35. Kowalski, C.H.; Beattie, S.R.; Fuller, K.K.; McGurk, E.A.; Tang, Y.W.; Hohl, T.M.; Obar, J.J.; Cramer, R.A. Heterogeneity Among Isolates Reveals That Fitness in Low Oxygen Correlates with Aspergillus fumigatus virulence. mBio 2016, 7, e01515-e01516. [CrossRef]

36. Iniguez, E.; Schocker, N.S.; Subramaniam, K.; Portillo, S.; Montoya, A.L.; Al-Salem, W.S.; Torres, C.L.; Rodriguez, F.; Moreira, O.C.; Acosta-Serrano, A.; et al. An $\alpha$-Gal-containing neoglycoprotein-based vaccine partially protects against murine cutaneous leishmaniasis caused by Leishmania major. PLoS Negl. Trop. Dis. 2017, 11, e0006039. [CrossRef]

37. Pfaffl, M. A new mathematical model for relative quantification in realtime RT-PCR. Nucleic Acids Res. 2001, 29, e45. [CrossRef]

38. Ye, J.; Coulouris, G.; Zaretskaya, I.; Cutcutache, I.; Rozen, S.; Madden, T. Primer-BLAST: A tool to design target-specific primers for polymerase chain reaction. BMC Bioinform. 2012, 13, 134. [CrossRef]

39. Galili, U.; LaTemple, D.C.; Radic, M.Z. A sensitive assay for measuring $\alpha$-Gal epitope expression on cells by a monoclonal anti-Gal antibody. Transplantation 1998, 65, 1129-1132. [CrossRef]

40. Pabst, O.; Mowat, A.M. Oral Tolerance to Food Protein. Mucosal Immunol. 2012, 5, 232-239. [CrossRef]

41. Commins, S.P. Mechanisms of Oral Tolerance. Pediatr. Clin. N. Am. 2015, 62, 1523-1529. [CrossRef]

42. Wambre, E.; Jeong, D. Oral Tolerance Development and Maintenance. Immunol. Allergy Clin. N. Am. 2018, 38, 27-37. [CrossRef] [PubMed]

43. Huibregtse, I.L.; Snoeck, V.; de Creus, A.; Braat, H.; De Jong, E.C.; Van Deventer, S.J.; Rottiers, P. Induction of Ovalbumin-Specific Tolerance by Oral Administration of Lactococcus Lactis Secreting Ovalbumin. Gastroenterology 2007, 133, 517-528. [CrossRef] [PubMed]

44. Huibregtse, I.L.; Marietta, E.V.; Rashtak, S.; Koning, F.; Rottiers, P.; David, C.S.; van Deventer, S.J.; Murray, J.A. Induction of Antigen-Specific Tolerance by Oral Administration of Lactococcus Lactis Delivered Immunodominant DQ8-restricted Gliadin Peptide in Sensitized Nonobese Diabetic Abo Dq8 Transgenic Mice. J. Immunol. 2009, 183, 2390-2396. [CrossRef] [PubMed]

45. Bennek, E.; Mandić, A.D.; Verdier, J.; Roubrocks, S.; Pabst, O.; Van Best, N.; Benz, I.; Kufer, T.; Trautwein, C.; Sellge, G. Subcellular Antigen Localization in Commensal E. Coli Is Critical for T Cell Activation and Induction of Specific Tolerance. Mucosal Immunol. 2019, 12, 97-107. [CrossRef] [PubMed]

46. Shanmugasundaram, R.; Selvaraj, R.K. Regulatory T Cell Properties of Chicken CD4+ CD25+ Cells. J. Immunol. 2011, 186, 1997-2002. [CrossRef]

47. Shanmugasundaram, R.; Selvaraj, R.K. Regulatory T Cell Properties of Thymic CD4+ CD25+ Cells in Ducks. Vet. Immunol. Immunopathol. 2012, 149, 20-27. [CrossRef]

48. Shanmugasundaram, R.; Selvaraj, R.K. Regulatory T Cell Properties of Thymic CD4+CD25 + Cells in Turkeys. Poult Sci. 2012, 91, 1833-1837. [CrossRef]

49. Zhang, A.H.; Yoon, J.; Kim, Y.C.; Scott, D.W. Targeting Antigen-Specific B Cells Using Antigen-Expressing Transduced Regulatory T Cells. J. Immunol. 2018, 201, 1434-1441. [CrossRef]

50. Hamadeh, R.M.; Jarvis, G.A.; Galili, U.; Mandrell, R.E.; Zhou, P.; Griffiss, J.M. Human natural anti-Gal IgG regulates alternative complement pathway activation on bacterial surfaces. J Clin Investig. 1992, 89, 1223-1235. [CrossRef]

51. Katopodis, A.G.; Warner, R.G.; Duthaler, R.O.; Streiff, M.B.; Bruelisauer, A.; Kretz, O.; Dorobek, B.; Persohn, E.; Andres, H.; Schweitzer, A.; et al. Removal of anti-Gal $\alpha 1,3 \mathrm{Gal}$ xenoantibodies with an injectable polymer. J. Clin. Investig. 2002, 110, 1869-1877. [CrossRef]

52. Pérez-Cruz, M.; Bello-Gil, D.; Costa, C.; Mañez, R. Cytokine profile associated with selective removal of natural anti- $\alpha$-Gal antibodies in a sepsis model in Gal-KO mice. Biochemistry 2017, 82, 205-212. 
53. Parente, R.; Doni, A.; Bottazzi, B.; Garlanda, C.; Inforzato, A. The complement system in Aspergillus fumigatus infections and its crosstalk with pentraxins. FEBS Lett. 2020, 28, 1873-3468. [CrossRef] [PubMed]

54. Ji, F.; Liu, Z.; Cao, J.; Li, N.; Liu, Z.; Zuo, J.; Chen, Y.; Wang, X.; Sun, J. B cell response is required for granuloma formation in the early infection of Schistosoma japonicum. PLoS ONE 2008, 3, e1724. [CrossRef] [PubMed]

55. Phuah, J.Y.; Mattila, J.T.; Lin, P.L.; Flynn, J.L. Activated B Cells in the Granulomas of Nonhuman Primates Infected with Mycobacterium tuberculosis. Am. J. Pathol. 2012, 181, 508-514. [CrossRef] [PubMed]

56. Phuah, J.; Wong, E.A.; Gideon, H.P.; Maiello, P.; Coleman, M.T.; Hendricks, M.R.; Ruden, R.; Cirrincione, L.R.; Chan, J.; Lin, P.L.; et al. Effects of B Cell Depletion on Early Mycobacterium tuberculosis Infection in Cynomolgus Macaques. Infect. Immun. 2016, 84, 1301-1311. [CrossRef] [PubMed]

57. Loxton, A.G. B cells and their regulatory functions during Tuberculosis: Latency and active disease. Mol. Immunol. 2019, 111, 145-151. [CrossRef] [PubMed]

58. Silva Miranda, M.; Breiman, A.; Allain, S.; Deknuydt, F.; Altare, F. The tuberculous granuloma: An unsuccessful host defence mechanism providing a safety shelter for the bacteria? Clin. Dev. Immunol. 2012, 2012, 139127. [CrossRef]

59. Bold, T.D.; Ernst, J.D. Who Benefits from Granulomas, Mycobacteria or Host? Cell 2009, 136, 17-19. [CrossRef]

60. Medzhitov, R.; Schneider, D.S.; Soares, M.P. Disease Tolerance as a Defense Strategy. Science 2012, 335, 936-941. [CrossRef]

61. Ayres, J.S.; Schneider, D.S. Tolerance of Infections. Annu. Rev. Immunol. 2012, 30, 271-294. [CrossRef]

62. Cooper, D.K.; Koren, E.; Oriol, R. Oligosaccharides and Discordant Xenotransplantation. Immunol. Rev. 1994, 141, 31-58. [CrossRef] [PubMed]

63. Palmetshofer, A.; Galili, U.; Dalmasso, A.P.; Robson, S.C.; Bach, F.H. $\alpha$-galactosyl Epitope-Mediated Activation of Porcine Aortic Endothelial Cells: Type II Activation. Transplantation 1998, 65, 971-978. [CrossRef] [PubMed]

64. Almeida, I.C.; Milani, S.R.; Gorin, P.A.; Travassos, L.R. Complement-mediated lysis of Trypanosoma cruzi trypomastigotes by human anti- $\alpha$-galactosyl antibodies. J. Immunol. 1991, 146, 2394-2400. [PubMed]

65. Portillo, S.; Zepeda, B.G.; Iniguez, E.; Olivas, J.J.; Karimi, N.H.; Moreira, O.C.; Marques, A.F.; Michael, K.; Maldonado, R.A.; Almeida, I.C. A Prophylactic $\alpha$-Gal-based Glycovaccine Effectively Protects against Murine Acute Chagas Disease. NPJ Vaccines 2019, 4, 13. [CrossRef]

66. Moura, A.P.V.; Santos, L.C.; Brito, C.R.N.; Valencia, E.; Junqueira, C.; Filho, A.A.; Sant'Anna, M.R.; Gontijo, N.F.; Bartholomeu, D.C.; Fujiwara, R.T.; et al. Virus-like particle display of the $\alpha$-Gal carbohydrate for vaccination against Leishmania Infection. ACS Cent. Sci. 2017, 3, 1026-1031. [CrossRef]

67. Pacheco, I.; Contreras, M.; Villar, M.; Risalde, M.A.; Alberdi, P.; Cabezas-Cruz, A.; Gortázar, C.; de la Fuente, J. Vaccination with $\alpha$-Gal protects against mycobacterial infection in the zebrafish model of tuberculosis. Vaccines 2020, 8, 195. [CrossRef]

68. Cabezas-Cruz, A.; de la Fuente, J. Immunity to $\alpha$-Gal: Toward a Single-Antigen Pan-Vaccine to Control Major Infectious Diseases. ACS Cent. Sci. 2017, 3, 1140-1142. [CrossRef]

69. Cabezas-Cruz, A.; de la Fuente, J. Immunity to $\alpha$-Gal: The Opportunity for Malaria and Tuberculosis Control. Front. Immunol. 2017, 8, 1733. [CrossRef]

70. Cabezas-Cruz, A.; Valdés, J.J.; de la Fuente, J. Control of vector-borne infectious diseases by human immunity against $\alpha$-Gal. Expert Rev. Vaccines 2016, 15, 953-955. [CrossRef]

(C) 2020 by the authors. Licensee MDPI, Basel, Switzerland. This article is an open access article distributed under the terms and conditions of the Creative Commons Attribution (CC BY) license (http://creativecommons.org/licenses/by/4.0/). 